\title{
Oxidation state of uranium in metamict and annealed zircon: near-infrared spectroscopic quantitative analysis
}

\author{
Ming Zhang ${ }^{1}$, Ekhard K H Salje ${ }^{1}$ and Rodney C Ewing ${ }^{2}$ \\ ${ }^{1}$ Department of Earth Sciences, University of Cambridge, Downing Street, \\ Cambridge CB2 3EQ, UK \\ 2 Department of Nuclear Engineering and Radiological Sciences, Department of Geological \\ Sciences, University of Michigan, Ann Arbor, MI 48109-2104, USA \\ E-mail: mz10001@esc.cam.ac.uk
}

Received 6 March 2003

Published 12 May 2003

Online at stacks.iop.org/JPhysCM/15/3445

\begin{abstract}
Radiation and thermally induced changes in the oxidation state of uranium in metamict zircon have been systematically analysed, for the first time, using polarized near-infrared spectroscopy. The results showed that in damaged zircon $U$ ions in crystalline domains exhibited relatively sharp, anisotropic signals from tetravalent and pentavalent $\mathrm{U}$ ions in crystalline domains $\left(\mathrm{U}_{\text {crystal }}^{4+}\right.$ and $\mathrm{U}_{\text {crystal }}^{5+}$ ). The linewidths and peak positions of the $4834 \mathrm{~cm}^{-1}$ band $\left(\mathrm{U}_{\text {crystal }}^{4+}, \boldsymbol{E} \| c\right)$ and the $6668 \mathrm{~cm}^{-1}$ band $\left(\mathrm{U}_{\text {crystal }}^{5+}, \boldsymbol{E} \perp c\right)$ are a nonlinear function of the self-radiation dose. They reach nearly constant values at doses greater than $\sim 3.5 \times 10^{18} \alpha$-events $\mathrm{g}^{-1}$. Quantitative analysis of $\mathrm{U}_{\text {crystal }}^{4+}$ and $\mathrm{U}_{\text {crystal }}^{5+}$ signals revealed that the intensity ratio $\left(\mathrm{U}_{\text {crystal }}^{4+} / \mathrm{U}_{\text {crystal }}^{5+}\right)$ exhibited a nearly linear increase as a function of dose and decreased on heating. This suggests that radiation leads to an alteration of the oxidation states of $U$ and the tetravalent state is more preferable in radiation-damaged zircons. $\mathrm{U}$ ions associated with amorphous materials ( $\mathrm{U}_{\text {amorphous}}$ ) gave rise to broad and isotropic signals and they were mainly in the tetravalent state $\left(\mathrm{U}_{\text {amorphous }}^{4+}\right)$, although small amounts of pentavalent $\mathrm{U}$ ions $\left(\mathrm{U}_{\text {amorphous }}^{5+}\right)$ may exist. The dose dependence of the intensity ratio of $U_{\text {amorphous }} / U_{\text {total }}$ did not follow that of the reported fraction of the amorphous domain, but gave clearly lower values. This implies the potential preferential occurrence of $U$ ions or possible $\mathrm{U}$ enrichment in the crystalline regions. Annealing intermediately and highly damaged zircon had different impacts on the oxidation state of $\mathrm{U}$. An intermediately damaged zircon (with a dose of $\sim 5.2 \times 10^{18} \alpha$-events $\mathrm{g}^{-1}$ ), annealed at high temperatures between 500 and $1800 \mathrm{~K}$, showed a systematic increase in the signals of $\mathrm{U}_{\text {crystal }}^{4+}$ and $\mathrm{U}_{\text {crystal }}^{5+}$ above $700 \mathrm{~K}$ while $\mathrm{U}_{\text {crystal }}^{4+}$ bands disappeared at temperatures above $1600 \mathrm{~K}$. In contrast, a highly damaged zircon
\end{abstract}


(with a dose of $\sim 15.9 \times 10^{18} \alpha$-events $\mathrm{g}^{-1}$ ) exhibited the presence of $\mathrm{U}_{\text {crystal }}^{4+}$ and $\mathrm{U}_{\text {crystal }}^{5+}$ above $1000 \mathrm{~K}$, with a dramatic increase in signals near $1400 \mathrm{~K}$.

\section{Introduction}

Zircon $\left(\mathrm{ZrSiO}_{4} ; \mathrm{I}_{1} /\right.$ amd $)$ has a structure that is built of chains of alternating $\mathrm{SiO}_{4}$ tetrahedra and $\mathrm{ZrO}_{8}$ triangular dodecahedra parallel to the $c$ axis (Speer 1980). U and Th are commonly found in natural zircon at concentrations that typically are no greater than $5000 \mathrm{ppm}$. Many zircon crystals are partially metamict (an aperiodic or amorphous state; Ewing 1994, Weber et al 1988, Salje et al 1999) as a result of self-radiation damage associated with the $\alpha$-decay events of the incorporated $\mathrm{U}$, Th and their daughter products.

Prior to this study there have been only limited studies of the effect of radiation damage on the oxidation state of uranium (Ellsworth 1925, Tomkeleff 1946, Hutton 1950, Frondel 1958). To gain an understanding of the oxidation state of $U$, which may occur in the tetra-, penta- and hexa-valent states, is of importance because the crystal chemistry and mobility of $U$ varies with oxidation state, and these processes can have a profound effect on the results of U/Pb dating. In addition, as pointed out in our recent study (Zhang et al 2002), U ion absorption spectra are very sensitive to local symmetry; thus, by monitoring the spectral variations of $U$ ions, one obtains an insight into local coordination environments as a function of increasing $\alpha$-decay dose. Chemical analyses by electron microprobe, mass spectroscopy and ion microprobe (e.g. recent studies by Chapman and Roddick 1994, Davis and Krogh 2000, Carrigan et al 2002, Geisler et al 2002) have been used to study U concentrations in zircon, particularly the loss of $U$ by diffusion and its effect on age determination. The bulk chemical analysis provides almost no structural or oxidation state information on uranium.

Although vibrational spectroscopy is sensitive to vibrational movements of molecules and atoms in crystals, the typical concentrations of $U$ in natural zircon (e.g. thousands of parts per million) are not high enough to cause significant changes in vibrational spectra (in the frequency region below $1500 \mathrm{~cm}^{-1}$ ). However, spectra related to the electronic state of $\mathrm{U}$ ions can be obtained in the near-infrared (NIR) region. In natural zircon, $\mathrm{U}$ atoms replace $\mathrm{Zr}$ atoms and occupy the $\mathrm{Zr}^{4+}$ site. The $\mathrm{Zr}^{4+}$ site is noncentrosymmetric, $\mathrm{D}_{2 \mathrm{~d}}$. Thus electronic transitions for paramagnetic impurities (e.g. U ions) are possible. Anderson and Payne (1939) and Anderson (1962, 1963) reported characteristic optical absorption spectra of $U$ ions in natural zircon. Experimental and theoretical work has been performed to gain an understanding of the energy levels of $\mathrm{U}$ ions; $\mathrm{U}^{4+}$ and $\mathrm{U}^{5+}$ spectra of $\mathrm{U}$-doped synthetic and heated natural zircon have been obtained (Judd and Runciman 1976, Kisliuk et al 1967, Richman et al 1967, Mackey et al 1975, Vance and Mackey 1974, 1975, 1978). The U energy levels can be labelled in terms of five irreducible representations of the $\mathrm{D}_{2 \mathrm{~d}}$ point group: four singlets $\Gamma_{1}, \Gamma_{2}, \Gamma_{3}, \Gamma_{4}$ and one doublet $\Gamma_{5}$. The degenerate $5 \mathrm{f}^{2}(S L) J$ terms split into 70 levels: $16 \Gamma_{1}+9 \Gamma_{2}+12 \Gamma_{3}+12 \Gamma_{4}+21 \Gamma_{5}$, i.e. 49 singlets $\Gamma_{1}, \Gamma_{2}, \Gamma_{3}, \Gamma_{4}$ and 21 doublets $\Gamma_{5}$.

In a recent NIR study on metamictization and recrystallization of zircon (Zhang et al 2002), we investigated the impact of radiation on defects (e.g. $\mathrm{U}$ and $\mathrm{OH}$ ions) in natural zircon and showed the evolution of $\mathrm{U}^{4+}$ and $\mathrm{U}^{5+}$ spectra, as well as modification of the $\mathrm{OH}$ signals with increasing degree of damage. The results showed that zircon samples with intermediate degrees of damage exhibited characteristic features that are different from those of crystalline or heavily damaged zircon. The changes, 'seen' by phonons (with a correlation length of a few unit cells) and defects such as $\mathrm{U}$ and $\mathrm{OH}$ ions, were explained by a radiation-induced change of local symmetry or a modification of the local configuration and a change of the oxidation state of uranium. 
As a continuation of this previous work (Zhang et al 2002), we report, in this paper, newly recorded data and further analysis of the $U$ ion spectra. We have obtained quantitative information on the spectral profiles of $U$ ions as a function of increasing damage and have extracted the different contributions related to $\mathrm{U}$ ions in aperiodic and crystalline domains. In this application of infrared spectroscopy to the study of radiation damage in zircon, we demonstrate that it is possible to separate the $\mathrm{U}$ signals related to recrystallized and amorphous regions and to obtain the ratio of the two types of signals as a function of the degree of radiation damage. To our knowledge, these results are the first of their kind. We have obtained a quantitative analysis of $U$ ion signals for metamict zircon and, by our analysis, have extracted the distribution of the different oxidation states of $U$ in crystalline and amorphous regions in metamict and recrystallized zircon.

\section{Experimental methods}

\subsection{Samples}

The samples used in this study were mainly gemstone zircons from Sri Lanka, previously investigated by a number of different analytical methods (e.g. x-ray diffraction, FT-Raman and micro-Raman spectroscopy, IR and micro-IR spectroscopy, electron microscopy, electron microprobe, nuclear magnetic resonance) (Ellsworth et al 1994, Farnan and Salje 2001, Murakami et al 1991, Ríos and Salje 1999, Ríos et al 2000, Salje et al 1999, Zhang and Salje 2001, 2003, Zhang et al 2000a, 2000b, 2000c, 2002). Detailed information on these samples can be found in these references. These samples were chosen because they are well-characterized crystals of gemstone quality, have low levels of chemical impurities and lack of growth zoning. More importantly, Sri Lankan zircons can be found which are either crystalline or metamict due to the wide range of $U$ and $T h$ concentrations found in these samples (Holland and Gottfried 1955). The crystals used in this study were further investigated using IR microscopy (beam sizes of $80-150 \mu \mathrm{m}$ ) and the results showed that the spectral variations from point to point were very small. Apart from these Sri Lankan crystals, gem-quality crystalline zircon crystals from other localities studied previously (crystal Mud Tank, from Australia, studied by Murakami et al 1991, and crystal Moroto, studied by Zhang et al 2000a, 2000b and Farnan and Salje 2001) as well as a gem crystal with unknown locality (originally labelled Vigene) were used for the low-temperature measurement. More detailed information on crystals Mud Tank and Moroto can be found in the references given above. Electron microprobe analysis showed that the crystal labelled Vigene consisted of $\mathrm{SiO}_{2} 33.39, \mathrm{ZrO}_{2} 66.59, \mathrm{HfO}_{2}$ $0.86, \mathrm{Y}_{2} \mathrm{O}_{3} 0.03, \mathrm{ThO}_{2} 0.01, \mathrm{UO}_{2} 0.01 \mathrm{wt} \%$, and $\mathrm{Fe}, \mathrm{Ca}$ and $\mathrm{Al}$ with concentrations below our detection level. Its lattice parameters $\left(a=6.6053 \AA, c=5.9802 \AA\right.$ and $\left.V=260.96 \AA^{3}\right)$ were determined by $\mathrm{x}$-ray Guinier powder diffraction with $\mathrm{Si}$ as internal standard. This sample showed polarized IR reflection features in the mid-IR region, similar to those of a crystalline zircon as reported by Zhang et al (2000c) and its reflectivity at $850 \mathrm{~cm}^{-1}(\boldsymbol{E} \perp \boldsymbol{c})$ is 0.97 , a value close to that of undamaged zircon (Zhang and Salje 2001). FT-Raman analysis (with an instrumental resolution of $\left.2 \mathrm{~cm}^{-1}\right)$ showed that its $v_{3}$ Raman mode $\left(\mathrm{B}_{1 \mathrm{~g}}\right.$, antisymmetric stretching) is located near $\sim 1007 \mathrm{~cm}^{-1}$ with a measured full width at half maximum (FWHM) of $\sim 4 \mathrm{~cm}^{-1}$. The radiation dose was estimated to be less than $1.0 \times 10^{18} \alpha$-events $\mathrm{g}^{-1}$ based on a comparison with published data (e.g. Holland and Gottfried (1955) and Murakami et al (1991)) for X-ray data, Zhang et al (2000b) for polarized IR data and Zhang et al (2000c) for Raman data). Natural zircon may be subjected to thermal annealing during geological periods, thus affecting the amount of radiation damage that is retained in the sample. In this study, the self-radiation dose (based on the age of the zircon and its $U$ and Th contents) for the natural 
zircon crystals has been used to characterize the amount of damage. At present this is the best parameter to use in determining the extent of damage and will allow us to assess the relative changes in the crystalline and metamict domains of the zircon crystals.

The crystallographic orientations of the crystals were determined from the external morphology or by using x-ray precession techniques and an optical polarizing microscope. It was impossible to orient samples with doses higher than $\sim 10 \times 10^{18} \alpha$-events $\mathrm{g}^{-1}$, as there were no easily obtained Bragg reflections and these high-dose crystals all had irregular external shapes. Crystal zircon plates were cut parallel to the $c$ axis and then polished. Thermally treated samples were prepared by annealing the sample between 500 and $1800 \mathrm{~K}$ in air in a vertical furnace. The annealing temperature was measured with a Pt-PtRh thermocouple that was placed just above the samples. The zircon was annealed at a high temperature for $1 \mathrm{~h}$ and then quenched in air. After measurements at room temperature, the samples were annealed at a higher temperature.

\section{Infrared technique}

Infrared spectra were recorded using two IR spectrometers. A Bruker FT-IR 66v spectrometer attached to an infrared microscope was used to record the infrared spectra between 500 and $13000 \mathrm{~cm}^{-1}$ at room temperature. A liquid-nitrogen-cooled MCT detector, coupled with a $\mathrm{KBr}$ beamsplitter and a Globar source, were used to record the spectra between 500 and $5000 \mathrm{~cm}^{-1}$. For the frequency region of 3000-11 $000 \mathrm{~cm}^{-1}$, a tungsten source, an MCT detector and $\mathrm{a} \mathrm{CaF}_{2}$ beamsplitter were used with spectral resolutions of 2 and $4 \mathrm{~cm}^{-1}$. A KRS5 wire-grid polarizer was employed. All the spectra were averaged over 512 scans. A Bruker 113v IFS spectrometer was used to record polarized and unpolarized infrared spectra between 4000 and $8000 \mathrm{~cm}^{-1}$ at low temperatures. An instrumental resolution of $1 \mathrm{~cm}^{-1}$ and 350 scans were adopted. A Leybold two-stage closed-cycle helium cryostat with a working temperature range of $13-310 \mathrm{~K}$ was used for the low-temperature measurements (Zhang et al 1996). The cryostat was coupled with a Leybold TLC60 temperature controller and a Leybold cryo-compresser. A sample holder was made from high-thermal-conductivity oxygen-free copper. A gold-coated lattice made from oxygen-free copper was installed at the sample position to improve the thermal contact between the sample and the sample holder. One temperature sensor, positioned near the heating unit, was used to control the temperature of the cryostat while another Si-diode temperature sensor (LakeShore, DT-470-DI-13, calibrated by the manufacturer) was glued onto the centre of the sample holder for measuring the sample temperature. The sample was placed in a vacuum chamber equipped with KRS5 windows. Sample and reference singlebeam spectra measured at the same temperatures and in the same polarization conditions were used for calculating the absorption spectra. All absorption spectra were recorded as absorbance $\alpha$, with $\alpha=-\log _{10}\left(I_{\text {sample }} / I_{\text {reference }}\right)$, where $I$ is the single-beam transmission intensity. The software OPUS-IR was used for data analysis. In order to obtain peak positions and FWHMs, the measured data were fitted to the Lorentzian functions with linear baselines.

\section{Analysis and results}

\subsection{Radiation-induced spectral changes}

Polarized U ion spectra (between 4000 and $11000 \mathrm{~cm}^{-1}$ ) of crystalline and metamict zircon are shown in figure 1(a). For crystalline zircon, our data are consistent with published results (Richman et al 1967, Vance and Mackey 1978), although some bands are too weak to be resolved at room temperature. We recorded absorption bands at 4838 and $10922 \mathrm{~cm}^{-1}$ in 
weakly damaged samples and they were assigned to $\mathrm{U}_{\text {crystal }}^{4+}$ (Richman et al 1967, Vance and Mackey 1978). We use the subscript 'crystal' to indicate that the signal is associated with crystalline $\mathrm{ZrSiO}_{4}$. The sharp bands near 6668 and $9030 \mathrm{~cm}^{-1}(\boldsymbol{E} \perp \boldsymbol{c})$ are assigned as signals due to $\mathrm{U}_{\text {crystal }}^{5+}$ in optical and Zeeman studies (Vance and Mackey 1974, 1975). Judd and Runciman (1976) proposed that they were due to $\Gamma_{6} \rightarrow \Gamma_{6}$ and $\Gamma_{7} \rightarrow \Gamma_{7}$ transitions. Experimental results (Vance and Mackey 1978) confirmed their prediction and revealed that there was no accidental degeneracy in the ground state of $U$ ions. These authors found that it was caused by impurity-induced new transitions. In a recent classical atomic simulation study of zircon using the energy minimization approach, Akhtar and Waseem (2001) calculated defect energies to predict the most favourable site for an impurity ion in the host lattice of zircon and found that pentavalent ions could exist in zircon by metal vacancy compensation or electron compensation mechanisms.

The impact of radiation on the $U$ ion spectra is characterized by three types of change described below.

(1) Isotropic, broad features appear in metamict zircon and their intensity increases with increasing degree of damage. As shown in figure 1(b), a broad feature occurs in the polarized spectra $\left(\boldsymbol{E} \| \boldsymbol{c}\right.$ and $\boldsymbol{E} \perp \boldsymbol{c}$ ) between 4000 and $5600 \mathrm{~cm}^{-1}$ in heavily damaged samples. This feature is assigned as $\mathrm{U}_{\text {amorphous }}^{4+}$ (the subscript 'amorphous' indicates that the signal is associated with the radiation-induced amorphous, or aperiodic, domains of $\mathrm{ZrSiO}_{4}$ ) absorption because they are absent in the crystalline sample and disappear when annealed at high temperatures. Although the $\mathrm{U}_{\text {amorphous }}^{4+}$ signals were the dominant components in spectra of high-dose samples (dose greater than $\sim 8 \times 10^{18} \alpha$-events $\mathrm{g}^{-1}$ ), a broad, isotropic feature also appeared near $6700 \mathrm{~cm}^{-1}$, but with a very weak intensity. The presence of this signal indicates that a small number of $U$ ions are in the pentavalent state $\left(\mathrm{U}_{\text {amorphous }}^{5+}\right)$ in metamict natural $\mathrm{ZrSiO}_{4}$. In highly damaged zircons, the ratio between the $\mathrm{U}_{\text {amorphous }}^{4+}$ and $\mathrm{U}_{\text {amorphous }}^{5+}$ absorption areas (integrated between 4500 and $5600 \mathrm{~cm}^{-1}$ for the $\mathrm{U}_{\text {amorphous }}^{4+}$ signal, and between 6200 and $7150 \mathrm{~cm}^{-1}$ for the $\mathrm{U}_{\text {amorphous }}^{5+}$ signal) gave an averaged value of $\sim 10 \%$.

(2) The characteristic bands of crystalline materials show a systematic broadening and frequency shift (figures 1 (a) and 2).

(3) The $\mathrm{U}_{\text {crystal }}^{5+}$ band near $6668 \mathrm{~cm}^{-1}$ shows a relatively strong response to radiation damage in comparison with $\mathrm{U}_{\text {crytstal }}^{4+}$ as it became almost unresolvable above $7.5 \times 10^{18} \alpha$-events $\mathrm{g}^{-1}$, while weak $\mathrm{U}_{\text {crystal }}^{4+}$ signals (e.g. near $4830 \mathrm{~cm}^{-1}$ ) are still preserved.

\subsection{Quantitative analysis of $U^{4+}$ and $U^{5+}$ signals}

Spectral subtractions were conducted to separate the signals associated with crystalline materials from those of amorphous phases. In this approach, the damaged zircon was treated as a two-phase system (although the effective medium approach (Zhang and Salje 2001) is usually a better method, the different $U$ concentrations in zircons with different degrees of damage made the application difficult). The subtraction was completed between two polarized spectra with different orientations recorded from the same crystal. The idea is based on the fact that, for a damaged sample, the signals related to crystalline regions remain essentially anisotropic even for damaged samples, whereas, signals from amorphous domains are independent of crystallographic orientations (i.e. the amorphization process destroys the long-range order of the crystal structure). Radiation-induced loss of anisotropy by metamictization of zircon has been shown previously by different studies, e.g. refractive index (Holland and Gottfried 


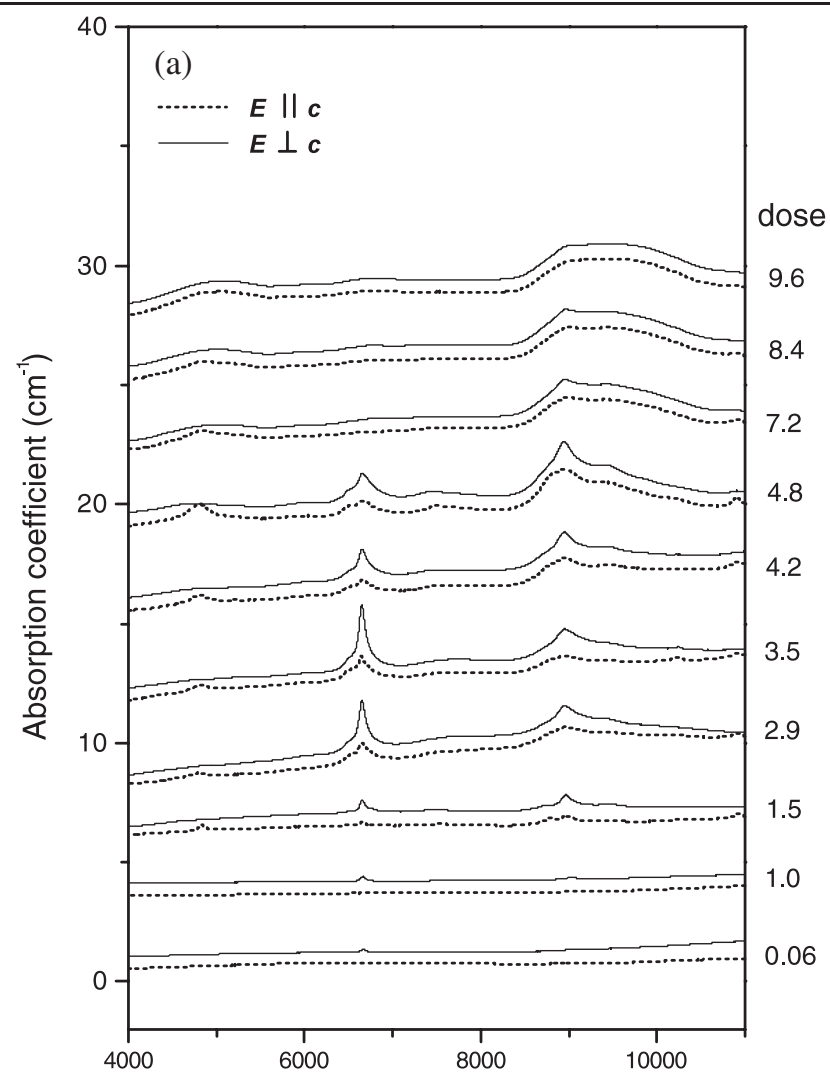

Wavenumber $\left(\mathrm{cm}^{-1}\right)$

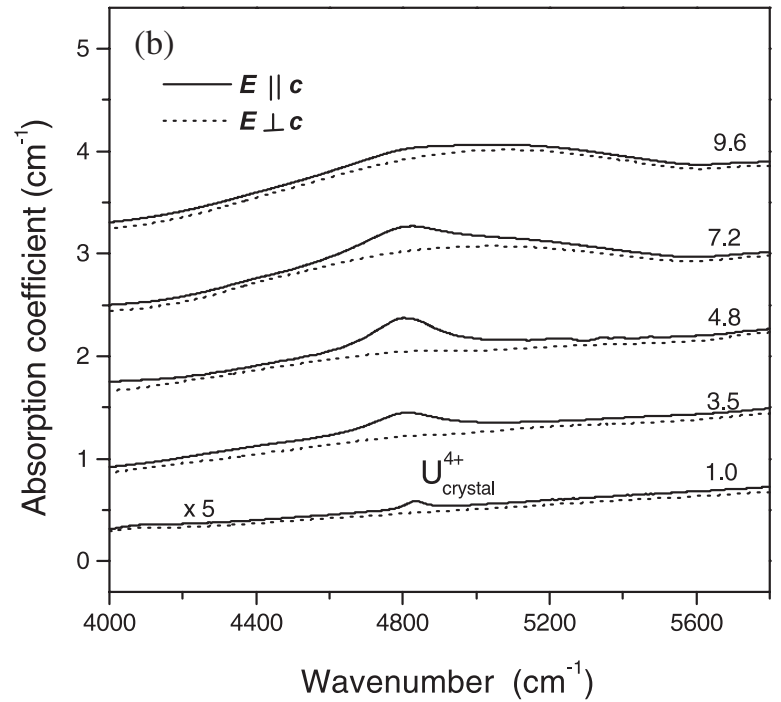

Figure 1. Polarized U ion spectra of metamict zircon (a) between 4000 and $11000 \mathrm{~cm}^{-1}$ (the NIR data are from Zhang et al 2002). The indicated radiation dose represents the self-radiation dose of the natural zircon crystals accumulated since their growth. (b) Detailed feature between 4000 and $5800 \mathrm{~cm}^{-1}$. The broad and isotropic $\mathrm{U}^{4+}$ feature in $4000-5600 \mathrm{~cm}^{-1}(\boldsymbol{E} \perp c)$ was produced by metamictization. 


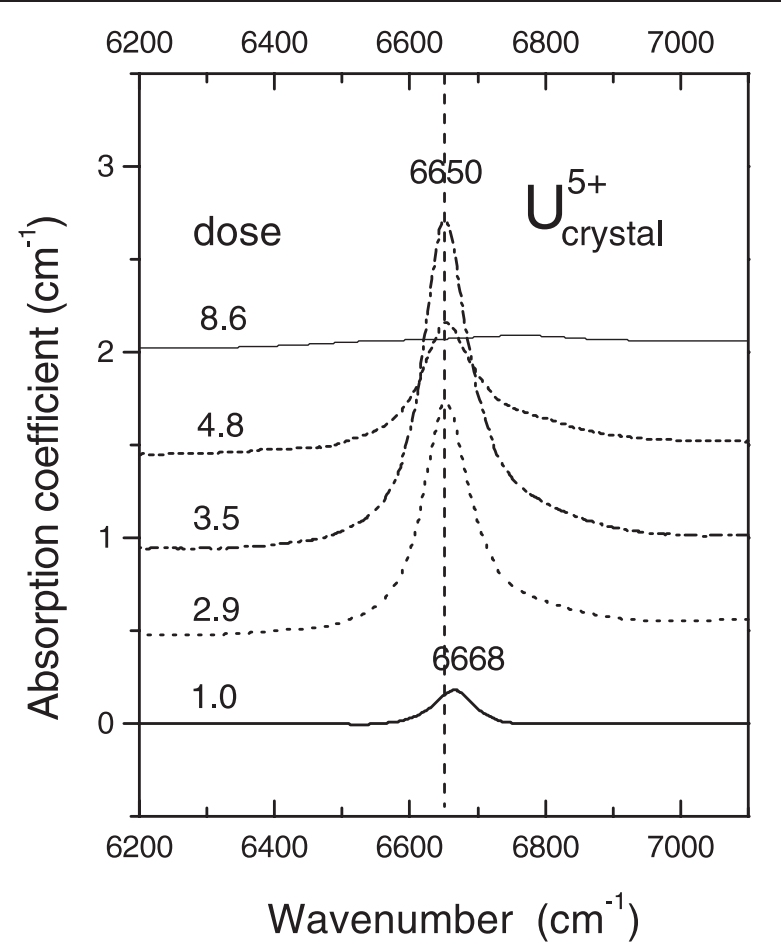

Figure 2. Difference spectra in the frequency region of $6200-7100 \mathrm{~cm}^{-1}\left(A_{E \perp c}-A_{E \| c}\right.$, where $A$ represents absorption spectra).

1955), electron microscopy (Murakami et al 1991, Meldrum et al 1998), polarized infrared spectroscopy in mid-IR (Zhang et al 2000c), far-IR (Zhang and Salje 2001) and near-IR (Zhang et al 2002). Similar methods were successfully used to separate the $\mathrm{OH}$ signals associated with crystalline phases from those of amorphous domains in metamict titanite (Salje et al 2000, Zhang et al 2001). The advantage of using difference spectra from the same crystal is that this method can reduce the possible errors related to the measurements of different samples and also avoids the potential uncertainty caused by spectral variations associated with the amorphous zircon under further bombardments. To acquire better data for spectral subtraction and integration, particularly for high dose cases in which very limited crystalline regions remain, special measures were taken. Polarized reference single-beam spectra for both $\boldsymbol{E} \| \boldsymbol{c}$ and $\boldsymbol{E} \perp \boldsymbol{c}$ were recorded first in identical experimental conditions except rotating the polarizer remotely or manually; then, after sample loading, polarized sample single-beam spectra were recorded in the same experimental conditions as used in the reference spectrum measurements. These measures resulted in essentially consistent baselines and signal-noise ratios. In particular, this method ensured that the data measured with $\boldsymbol{E} \| \boldsymbol{c}$ and $\boldsymbol{E} \perp \boldsymbol{c}$ are from the same sample areas, with identical optical paths and sample thicknesses. These factors might affect the outcome of the subtractions and peak profile analysis (curve fit and integration). Typical difference spectra obtained through the spectrum subtraction are plotted in a stack in figures 2 and 3(a) (the inset part). The reasonable baselines and bandshapes suggest that the measurements and subtractions were well performed.

The $4834 \mathrm{~cm}^{-1}$ band $\left(\mathrm{U}_{\text {crystal }}^{4+}, \boldsymbol{E} \| \boldsymbol{c}\right.$ ) and the $6668 \mathrm{~cm}^{-1}$ band $\left(\mathrm{U}_{\text {crystal }}^{5+}, \boldsymbol{E} \perp \boldsymbol{c}\right.$ ) were used mainly for spectral analysis, as they are relatively intense and better separated from the 

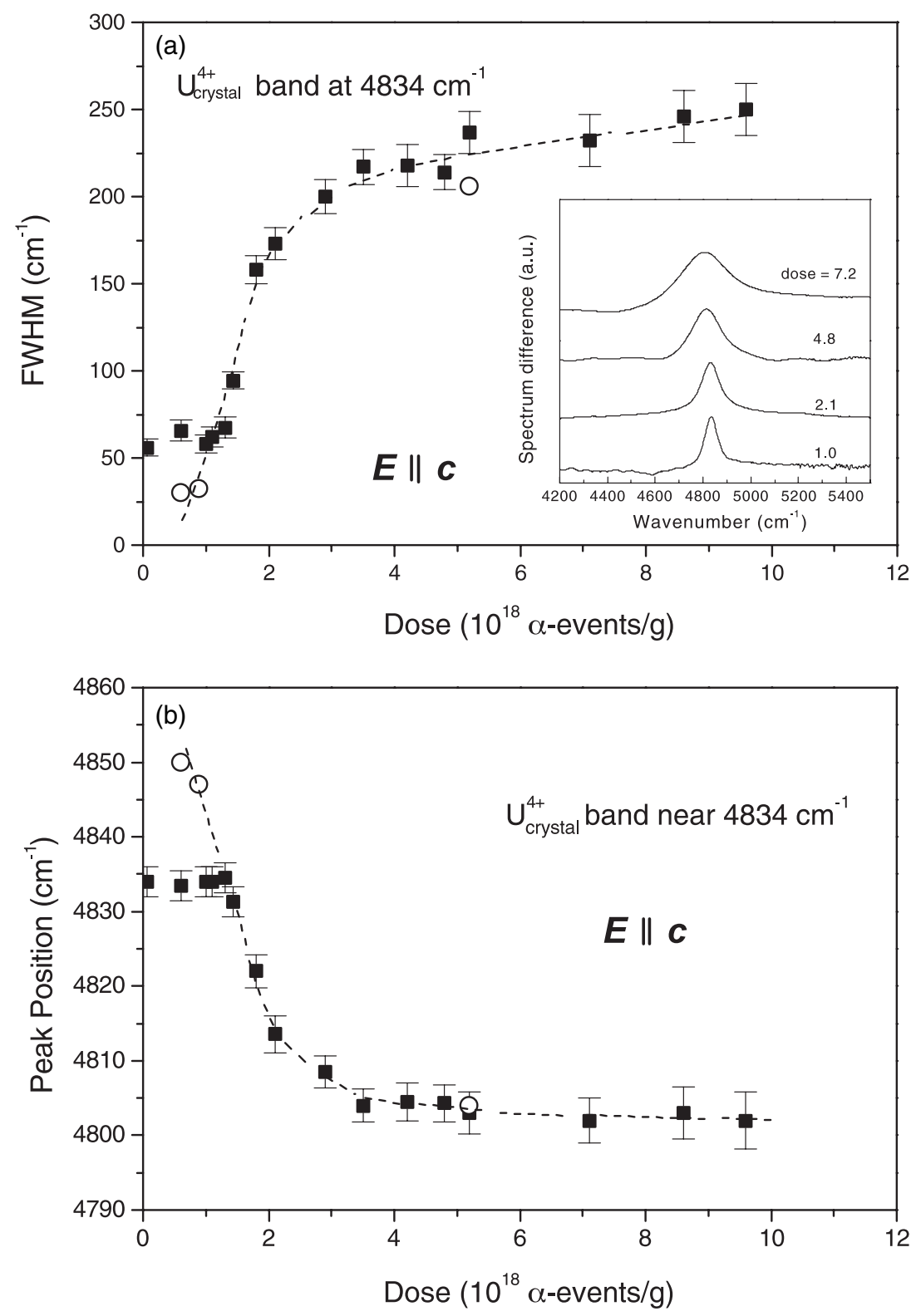

Figure 3. Dose dependence of peak positions and FWHM obtained from Sri Lanka zircon (full squares represent data obtained at room temperature, and open circles at $20 \mathrm{~K}$ ): (a) FWHM of the $4834 \mathrm{~cm}^{-1}$ band $\left(\mathrm{U}_{\text {crystal }}^{4+}\right)$; (b) peak position of the $4834 \mathrm{~cm}^{-1}$ band; and (c) peak position of the $\mathrm{U}_{\text {crystal }}^{5+}$ band near $6668 \mathrm{~cm}^{-1}$. The inset in figure 3(a) shows the difference spectra between 4200 and $5500 \mathrm{~cm}^{-1}\left(A_{E \| c}-A_{E \perp c}\right.$, $)$, which are normalized to show detailed changes of the band. The curves are visual guides.

other bands. Peak profile analysis was performed by fitting the $\mathrm{U}_{\text {crystal }}^{4+}$ and $\mathrm{U}_{\text {crystal }}^{5+}$ bands in the difference spectra to Lorentzian functions with linear baselines so as to gain quantitative results from the measured data. The FWHMs and peak positions of the $\mathrm{U}_{\text {crystal }}^{4+}$ and $\mathrm{U}_{\text {crystal }}^{5+}$ 


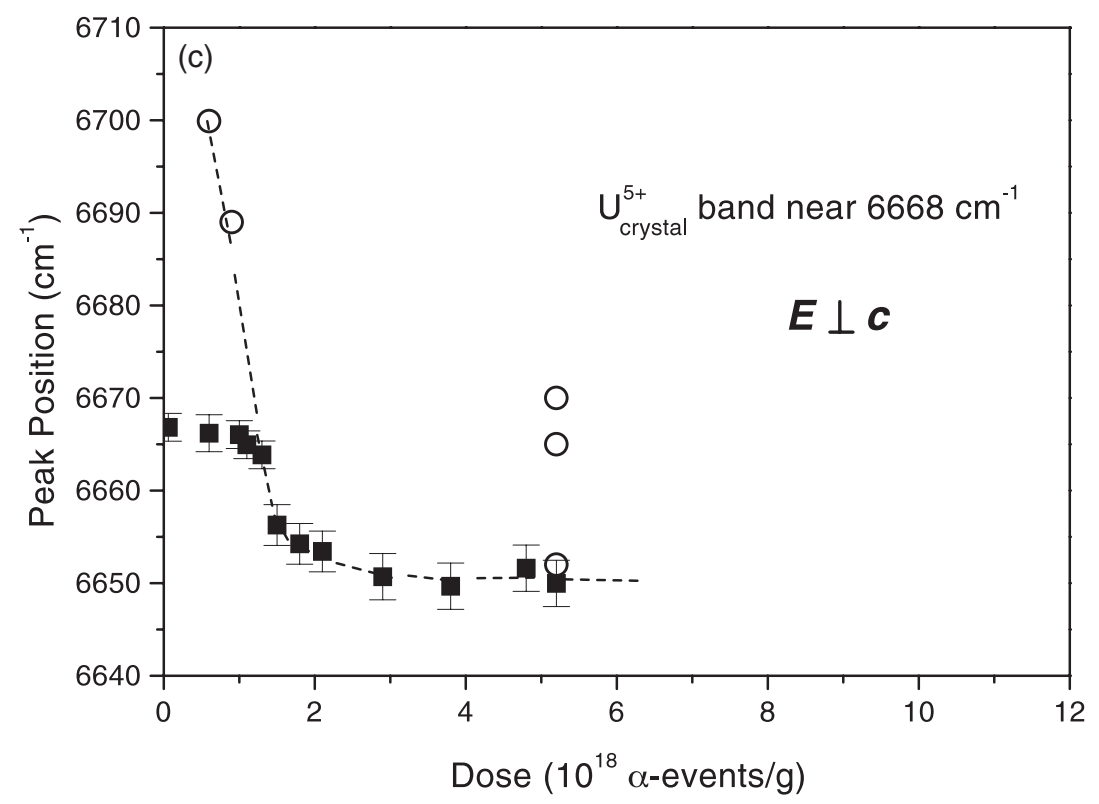

Figure 3. (Continued.)

are plotted as a function of radiation dose in figures 3(a)-(c). As the data were obtained from the difference spectra and the contributions of the amorphous domains were removed by spectral subtraction, the changes shown in figures 3(a)-(c) reflect mainly the behaviour of $\mathrm{U}$ ions in the crystalline regions. The peak profiles of the $\mathrm{U}_{\text {crystal }}^{4+}$ near $4834 \mathrm{~cm}^{-1}$ shows a non-linear change with radiation dose (figure 3(a)). With increasing dose, its FWHM exhibits a dramatic increase in the dose region of $\sim 0$ and $\sim 3.5\left(10^{18} \alpha\right.$-events $\left.\mathrm{g}^{-1}\right)$, as shown in figure 3(a). It becomes almost saturated with further increasing dose. We consider that the dramatic frequency change and line-broadening in these $\mathrm{U}$ ion bands has the same physical nature as those frequency changes in Raman bands (e.g. the $v_{3}$ mode near $1007 \mathrm{~cm}^{-1}$ as reported by Zhang et al $(2000 \mathrm{c}))$ that occur in the same dose region. They are associated with radiation-induced defective lattices. But the room-temperature data with doses of less than $1.0\left(10^{18} \alpha\right.$-events $\left.\mathrm{g}^{-1}\right)$ (figures 3(a)-(c)) are of a more complex nature. We noted with surprise that, for crystalline zircon, the bands show FWHM values of $50-60 \mathrm{~cm}^{-1}$ at room temperature. This observation led us to suspect that these crystalline zircons could be more damaged than we had initially estimated. Our low-temperature results at $20 \mathrm{~K}$ (open circles) show that the plateau shown in figures 3(a) and (b) in this low-dose region is mainly caused by temperature-induced line broadening or frequency shift rather than, or weakly related to, radiation damage or structural disordering.

One of the important observations from this study is that in metamictization the $\mathrm{U}_{\text {crystal }}^{5+}$ band near $6668 \mathrm{~cm}^{-1}(\boldsymbol{E} \perp \boldsymbol{c})$ showed a much stronger decrease in intensity than that the $\mathrm{U}_{\text {crystal }}^{4+}$ band near $4834 \mathrm{~cm}^{-1}(\boldsymbol{E} \| \boldsymbol{c})$ and the former became almost undetectable near a dose of $7.5\left(10^{18} \alpha\right.$-events $\left.\mathrm{g}^{-1}\right)$ while for $\mathrm{U}_{\text {crystal }}^{4+}$ the signal remained relatively intense. In order to compare the two types of signals quantitatively, the band areas of both signals were obtained by integrating the data shown in the difference spectra (figures 1(b) and 2). The ratio between these two band areas is plotted to reveal their relative change (figure 4(a)). The dose dependence of the ratio shows a systematic increase with increasing degree of damage. As the 
data were extracted from the signals mainly related to crystalline regions, the results shown in figure 4(a) represent changes occurring in the remaining crystalline domains. We were unable to obtain data points at doses higher than $\sim 7.5\left(10^{18} \alpha\right.$-events $\left.\mathrm{g}^{-1}\right)$, because the relatively sharp $\mathrm{U}_{\text {crystal }}^{5+}$ signal becomes undetectable in the difference spectra (figure 2) as described earlier. With increasing radiation dose, the systematic change of the ratio between $\mathrm{U}_{\text {crystal }}^{4+}$ and $\mathrm{U}_{\text {crystal }}^{5+}$ ions implies radiation-induced variations of local charge state. We shall show in a later section that, during high-temperature annealing, the intensity ratio between $\mathrm{U}_{\text {crystal }}^{4+}$ and $\mathrm{U}_{\text {crystal }}^{5+}$ exhibits an opposite change: a systematic increase, indicating that the change shown in figure 4(a) is caused by radiation damage.

The ratio of the $U$ ion signals contributed by those $U$ ions in amorphous volumes $\left(\mathrm{U}_{\text {amorphous }}=\mathrm{U}_{\text {amorphous }}^{4+}+\mathrm{U}_{\text {amorphous }}^{5+}\right)$ and the total $\mathrm{U}$ ions $\left(\mathrm{U}_{\text {total }}=\mathrm{U}_{\text {amorphous }}+\mathrm{U}_{\text {crystal }}^{4+}+\mathrm{U}_{\text {crystal }}^{5+}\right)$ was estimated (figure 4(b)). We found that it was very difficult or impossible to trace or integrate the $\mathrm{U}_{\text {amorphous }}^{5+}$ component in zircon with intermediate degrees of damage, because of the low intensity of the component and the presence of weak sharp bands in the region, even for $\boldsymbol{E} \| \boldsymbol{c}$. In all our determinations of the $\mathrm{U}_{\text {amorphous }}^{5+}$, the contribution of $\mathrm{U}_{\text {amorphous }}^{5+}$ was considered as $10 \%$ of the $\mathrm{U}_{\text {amorphous }}^{4+}$ (see above) value obtained from highly damaged samples (i.e. it was assumed that the ratio of $\mathrm{U}_{\text {amorphous }}^{4+}$ to $\mathrm{U}_{\text {amorphous }}^{5+}$ was a constant value in amorphous domains). This assumption is unlikely to result in any significant errors or influence our determination of the ratio, because the $\mathrm{U}_{\text {amorphous }}^{5+}$ signal is very weak and plays a much less important role in the ratio.

\subsection{U ion spectrum of decomposed zircon}

To compare the spectral difference between metamict and decomposed zircon, we measured a decomposed zircon crystal from an unknown locality. The crystal (sample Cam1) was previously studied using Raman, $x$-ray and infrared (Zhang et al 2000c, 2002). The sample is a green gemstone, like most of the heavily damaged samples analysed. However, it shows Raman signals of $\mathrm{ZrSiO}_{4}$ and additional sharp Raman bands at 146, 260, 312, 460 and $642 \mathrm{~cm}^{-1}$, characteristic of tetragonal $\mathrm{ZrO}_{2}$. X-ray diffraction data of Zhang et al $(2000 \mathrm{c})$ revealed that this zircon crystal is only partially metamict (with cell parameters $a=6.6070 \AA, c=6.0221 \AA$ ) and confirmed the presence of significant amounts of crystalline $\mathrm{ZrO}_{2}$, consistent with infrared and Raman data. This decomposed zircon exhibits multi-phonon (overtone and combination) bands very different from the metamict zircon due to the presence of glassy $\mathrm{SiO}_{2}$ (Zhang et al 2002). The $U$ ion spectra of this crystal exhibit well-resolved spectral features and sharp $U$ ions bands in contrast to other partially damaged samples (figure 5). The $\mathrm{U}_{\text {crystal }}^{5+}$ signal near $6650 \mathrm{~cm}^{-1}$ is almost undetectable in this sample. Based on the high-temperature data, which shall be described in a later section, we consider that this decomposed sample was subjected to high temperature annealing.

\subsection{Low-temperature spectra}

Low-temperature measurements in the near-IR were completed with two objectives:

(1) to check whether radiation damage or structural disorder was responsible for the large room-temperature values $\left(\sim 50-60 \mathrm{~cm}^{-1}\right)$ of the FWHMs recorded in crystalline samples (e.g. figure 3(a)), and

(2) to compare $\mathrm{U}$ ion spectra of crystalline and metamict zircon at low temperatures.

The low-temperature near-IR spectra from two samples with different degrees of damage are shown in figures 6(a) and (b) (with $\boldsymbol{E} \| \boldsymbol{c}$ ), and 6(c) and (d) (with $\boldsymbol{E} \perp \boldsymbol{c}$ ). Because U 

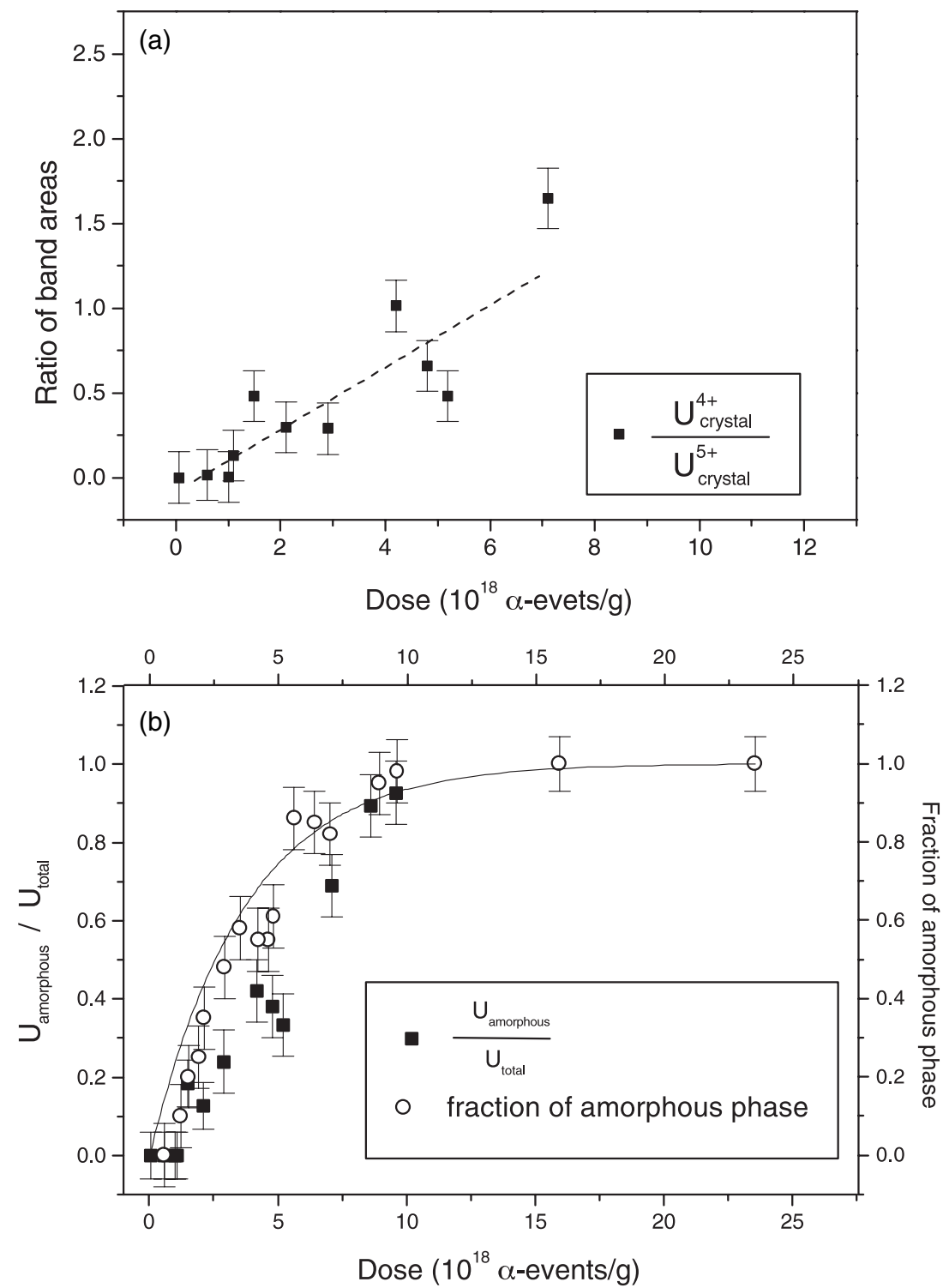

Figure 4. Dose dependence of the ratios of band areas (integrated absorption coefficients in units of $\mathrm{cm}^{-2}$ ): (a) between the bands near $4834 \mathrm{~cm}^{-1}\left(\mathrm{U}_{\text {crystal }}^{4+}\right)$ and near $6668 \mathrm{~cm}^{-1}\left(\mathrm{U}_{\text {crystal }}^{5+}\right)$ (the data were obtained by integration of the bands in difference spectra; the line is a visual guide); (b) $\mathrm{U}_{\text {amorphous }} / \mathrm{U}_{\text {total }}$ (full squares) in comparison with the fraction of the amorphous materials (open circles- the IR data from Zhang and Salje 2001). The line is the function $f=1-\mathrm{e}^{-B_{a} D}$ where $D$ is radiation dose and $B_{a}=2.7(3) \times 10^{-19} \mathrm{~g}$ is the amount of amorphous material produced per alpha-recoil (Ríos et al 2000).

concentrations in crystalline zircon are generally low $\left(\mathrm{UO}_{2}<0.01 \mathrm{wt} \%\right.$ for our crystalline Sri Lanka zircon) and all our crystalline zircon crystals from Sri Lanka are very thin (100-200 $\mu \mathrm{m}$ in thickness), low-temperature U ion data from these Sri Lanka crystalline zircons did not give good signal-to-noise ratios in the polarized measurements. In addition, a relatively large crystal (sample Vigene with estimated dose of less than $1.0 \times 10^{18} \alpha$-events $\mathrm{g}^{-1}$ 


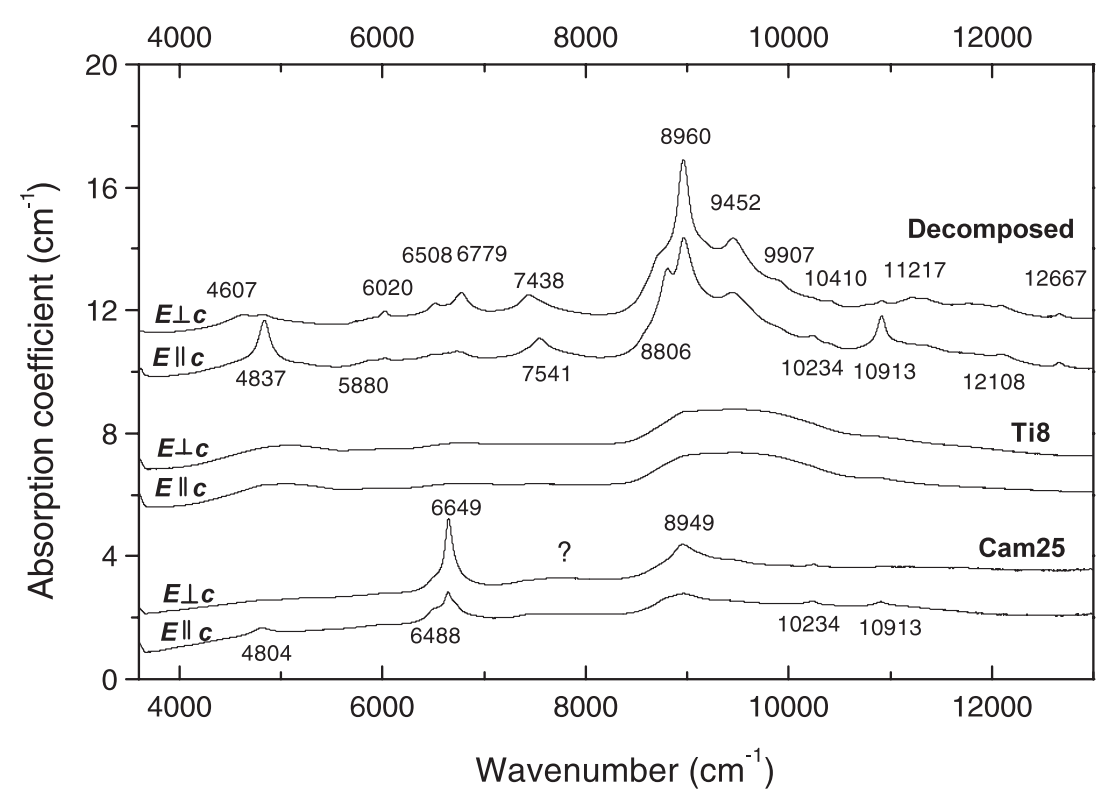

Figure 5. Comparison of U ion spectra of a decomposed zircon (Cam1), highly metamict zircon (Ti8) and a partially metamict zircon (Cam25).

and thickness of $4.7 \mathrm{~mm}$ ) from an unknown locality was used. This sample shows two very weak bands $\left(\boldsymbol{E} \| \boldsymbol{c}\right.$ ) located near 4072 and $4262 \mathrm{~cm}^{-1}$, and both appear to have a similar intensity at room temperature. These two signals were not reported in previous studies and they could hardly be seen in our thin plates of Sri Lanka zircons. They might be due to the electronic transitions of $U$ ions, because bands at 4032 and $4337 \mathrm{~cm}^{-1}$ were predicted by the calculation of Richman et al (1967), or they may be attributed to the combination of $\mathrm{OH}$ stretching and the vibrations of the framework.

The effect of cooling on $U$ ion spectra is dramatic for this crystalline zircon (Vigene) (figures 6(b) and (d)). Although the sample shows a $\mathrm{U}_{\text {crystal }}^{5+}$ band near $6668 \mathrm{~cm}^{-1}$ with a width of about $60 \mathrm{~cm}^{-1}$ at room temperature, the width decreases dramatically to $3.5 \mathrm{~cm}^{-1}$ at $20 \mathrm{~K}$ and the band shifts to $6700 \mathrm{~cm}^{-1}$. The linewidth and frequency as a function of temperature were obtained by curve fitting (figures 7(a) and (b)). The linear correlation between the FWHM and temperature and the fact that it passes through the origin at $0 \mathrm{~K}$ indicates that for crystalline zircon large values of FWHMs at room temperature are simply caused by thermal vibration rather than the structural disordering. These results confirm that the crystalline samples used in this study are almost undamaged. However, in crystalline zircon crystals from Sri Lanka, Mud Tank and Moroto the $\mathrm{U}^{4+}$ band near $4834 \mathrm{~cm}^{-1}$ showed unexpected FWHMs of $\sim 30 \mathrm{~cm}^{-1}$ at $20 \mathrm{~K}$.

In contrast to the crystalline zircon, decreasing temperature shows a much weaker effect on the $U$ ion spectra of the partially damaged sample Cam25 $\left(\sim 5.2 \times 10^{18} \alpha\right.$-events $\left.\mathrm{g}^{-1}\right)$ (figures 6(a) and (c)). The $\mathrm{U}_{\text {crystal }}^{5+}$ feature near $6651 \mathrm{~cm}^{-1}$ (the value at room temperature) of the sample becomes asymmetric at low temperatures. The bandshape seems to suggest that it consists of more than one band: one local maximum centred at $6670 \mathrm{~cm}^{-1}$ and the other two broad shoulders near 6665 and $6652 \mathrm{~cm}^{-1}$ (figures 3(c) and 6(c)). At $20 \mathrm{~K}$ the $\mathrm{U}_{\text {crystal }}^{4+}$ band near $3802 \mathrm{~cm}^{-1}$ becomes sharper but its peak position is almost unchanged. The different temperature dependence of the near-IR signals between crystalline and metamict materials 

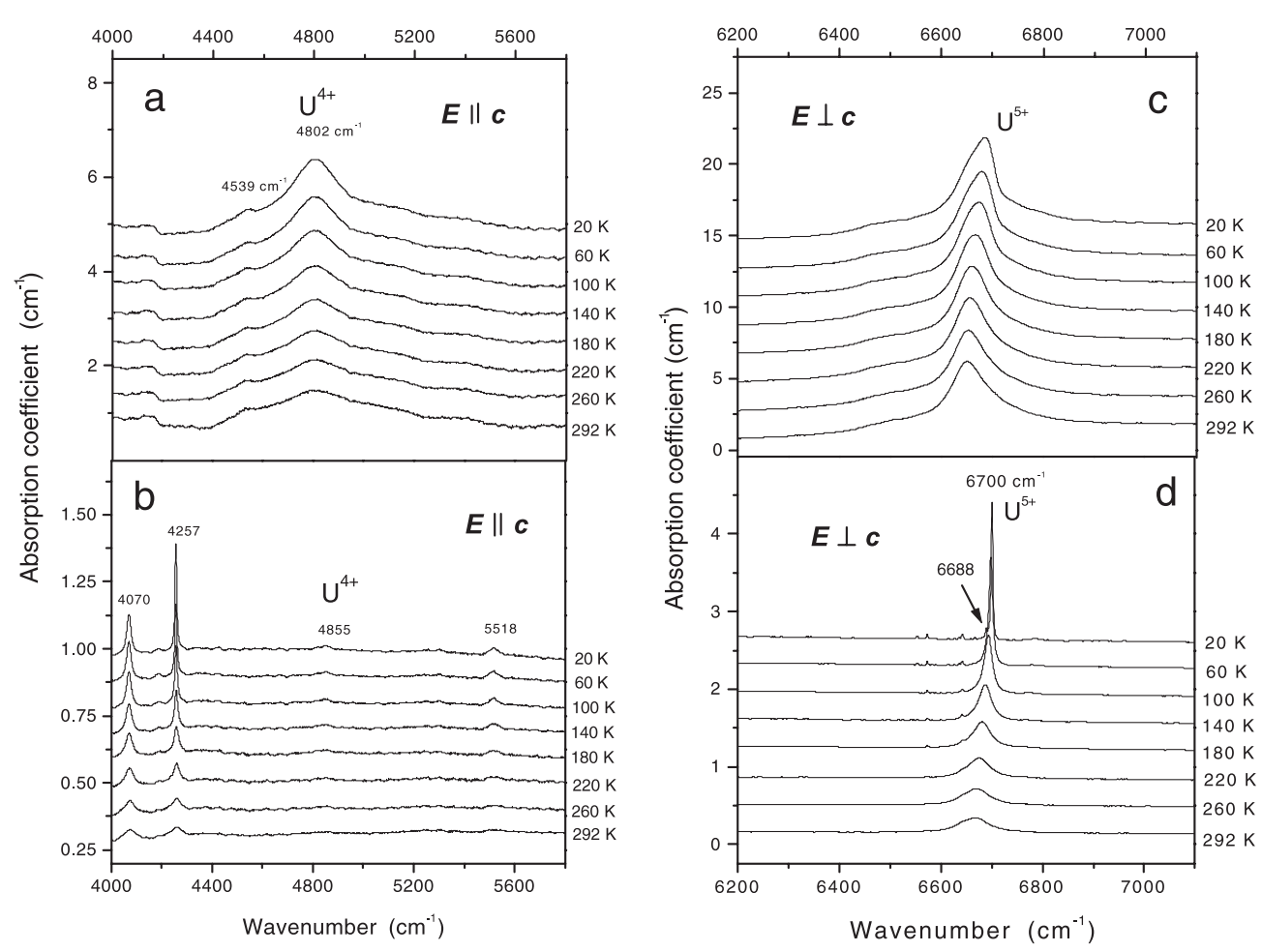

Figure 6. Polarized U ion spectra between 20 and $300 \mathrm{~K}$. (a) Partially damaged zircon (Cam25, dose $=5.2 \times 10^{18} \alpha$-events $\left.\mathrm{g}^{-1}\right), 4000-5800 \mathrm{~cm}^{-1}(\boldsymbol{E} \| \boldsymbol{c})$; (b) crystalline zircon (Vigene, estimated dose $<1.0 \times 10^{18} \alpha$-events $\left.\mathrm{g}^{-1}\right), 4000-5800 \mathrm{~cm}^{-1}(\boldsymbol{E} \| \boldsymbol{c})$; (c) partially damaged zircon (Cam25), 6200-7100 cm $\mathrm{cm}^{-1}\left(\boldsymbol{E} \perp \boldsymbol{c}\right.$ ); (d) crystalline zircon (Vigene), 6200-7100 cm $\mathrm{cm}^{-1}(\boldsymbol{E} \perp \boldsymbol{c})$.

is a result of radiation-induced structural variations between the crystalline and amorphous materials. Similar low-temperature behaviours were reported in $\mathrm{OH}$ species of crystalline and metamict zircons (Zhang et al 2002) and metamict titanites (Zhang et al 2000d).

For the crystalline sample shown in figure 6(b), a number of weak and sharp bands (near $6553,6572,6614,6626,6635,6642,6658,6667$ and $6689 \mathrm{~cm}^{-1}$, with widths of $2-10 \mathrm{~cm}^{-1}$ at $20 \mathrm{~K}$ ) were also detected at low temperatures. Changing temperature appears to have little impact on their frequencies. The physical nature of these weak bands is unclear. The possible causes include absorption bands by other rare-earth elements or new radiation-induced signals because some of them appear to be isotropic (they appear in both $\boldsymbol{E} \| \boldsymbol{c}$ and $\boldsymbol{E} \perp \boldsymbol{c}$ conditions with close intensities).

\subsection{The effect of thermal annealing on $U$ ion spectra}

Metamict zircons were thermally annealed between 500 and $1800 \mathrm{~K}$ for $1 \mathrm{~h}$ in order to understand the response of $\mathrm{U}$ ions to heating and to investigate the different thermal effects on $\mathrm{U}$ ions for zircons with different degrees of damage. Annealed zircon crystals were quenched on the lab bench and measured at room temperature before heating to a higher temperature. Two Sri Lankan zircon crystals were used in the study. One was partially damaged (sample Cam25, $\sim 5.2 \times 10^{18} \alpha$-events $\mathrm{g}^{-1}$ ) and the other is highly metamict (sample Sd4, $\sim 15.9 \times 10^{18} \alpha$-events $\mathrm{g}^{-1}$ ). Our results show that the thermal behaviour of $\mathrm{U}$ ions depends 


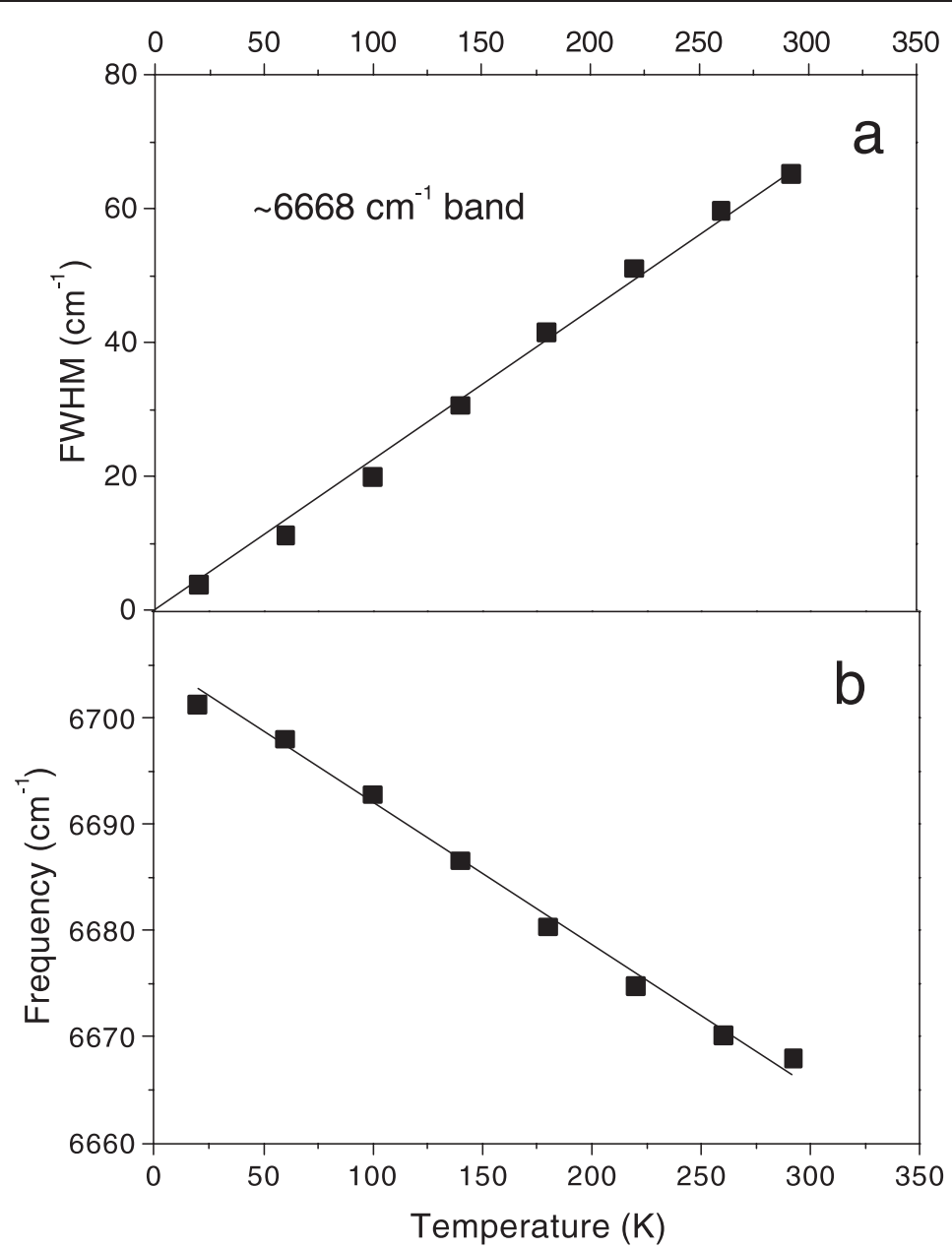

Figure 7. Temperature evolution of the peak profiles of the band near $6669 \mathrm{~cm}^{-1}$ : (a) FWHM, and (b) peak position. The lines are visual guides.

on the initial degree of damage of the samples. Thus, we shall describe the changes in partially and highly metamict zircon separately. As shown in figures 8(a)-(d), annealing a partially metamict sample (Cam25) at $500 \mathrm{~K}$ did not cause detectable spectral changes. Dramatic modifications of the spectra occurred near 1000 and $1600 \mathrm{~K}$. We noted that $U_{\text {crystal }}^{4+}$ and $U_{\text {crystal }}^{5+}$ signals show the following different types of changes on heating:

(1) The signals characteristic of crystalline materials show an increase in intensity (integrated absorption) taking place near $600 \mathrm{~K}$. However, the $\mathrm{U}_{\text {crystal }}^{4+}$ signal near $4830 \mathrm{~cm}^{-1}$ did not show a significant increase in intensity until $800 \mathrm{~K}$ (figures 8(a) and 10(b)), although it exhibits band sharpening at temperatures above $700 \mathrm{~K}$.

(2) A band near $9804 \mathrm{~cm}^{-1}(\boldsymbol{E} \| \boldsymbol{c}$ ) becomes active between 1000 and $1100 \mathrm{~K}$, and it shows an increase in intensity with further heating. The physical origin of this band is unclear.

(3) At temperatures between 1500 and $1600 \mathrm{~K}$, the $\mathrm{U}_{\text {crystal }}^{4+}$ bands at 4832, 8796 and $10916 \mathrm{~cm}^{-1}(\boldsymbol{E} \| \boldsymbol{c})$ disappeared (figure 8(a)), accompanied by a frequency shift of the $9018 \mathrm{~cm}^{-1}$ signal. 

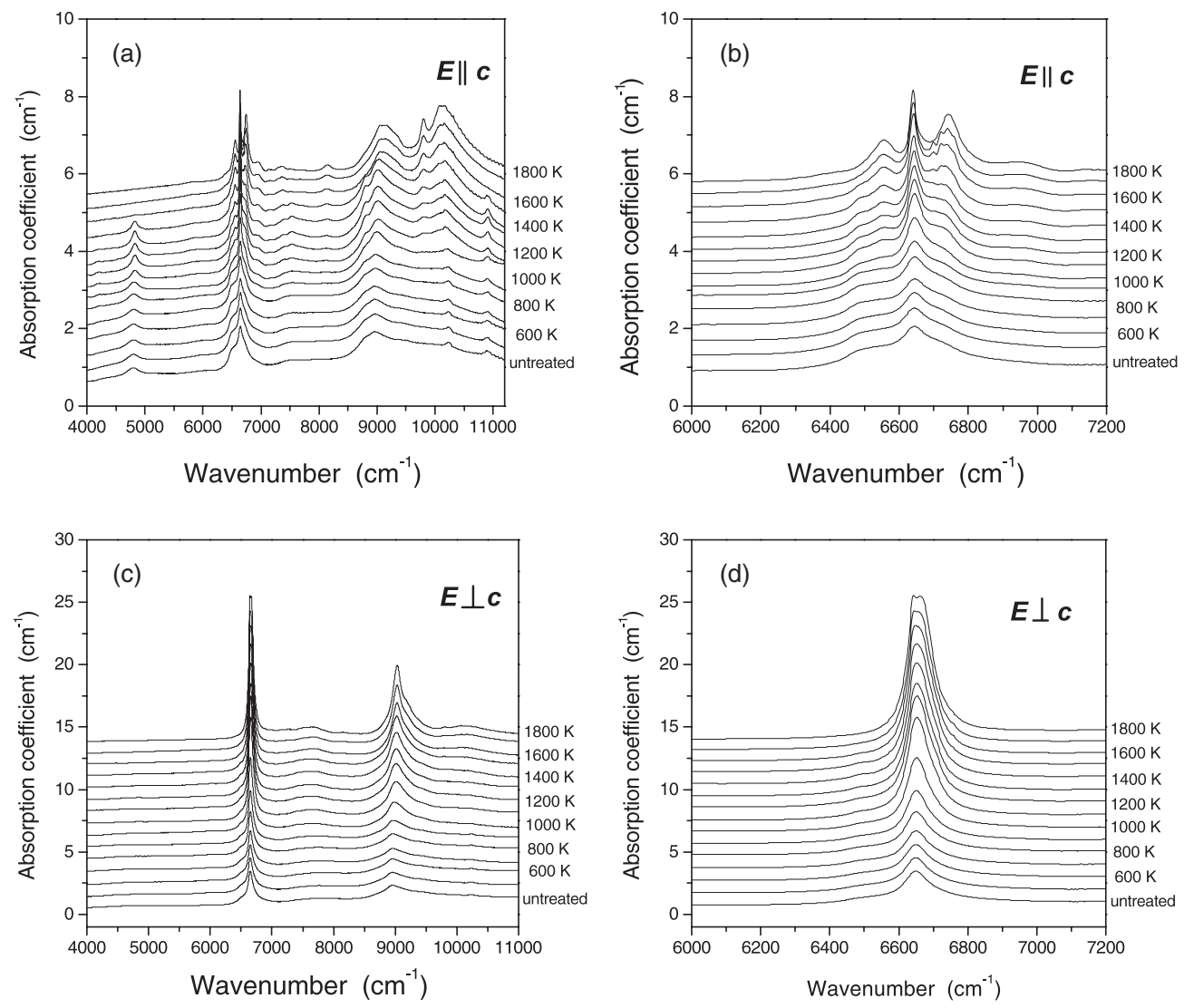

Figure 8. Polarized U ion spectra of a partially metamict zircon (Cam25) annealed between 500 and $1800 \mathrm{~K}$. (a) Between 4000 and $11000 \mathrm{~cm}^{-1}(\boldsymbol{E} \| \boldsymbol{c})$; (b) detailed changes between 6000 and $7200 \mathrm{~cm}^{-1}(\boldsymbol{E} \| \boldsymbol{c})$; (c) between 4000 and $11000 \mathrm{~cm}^{-1}(\boldsymbol{E} \perp \boldsymbol{c})$; and (d) detailed changes between 6000 and $7200 \mathrm{~cm}^{-1}(\boldsymbol{E} \perp \boldsymbol{c})$.

We recorded a few unexpected weak and sharp absorption bands. They appeared near 6698, 6721,6740 and $6759 \mathrm{~cm}^{-1}$ between 1500 and $1700 \mathrm{~K}$. Above $1600 \mathrm{~K}$, the $\mathrm{U}_{\text {crystal }}^{5+}$ band near $6650 \mathrm{~cm}^{-1}(\boldsymbol{E} \perp \boldsymbol{c})$ appears to become two local maxima (figure 8(c)). More detailed changes in the region of 6000 and $7200 \mathrm{~cm}^{-1}$ can be seen in figures 8(b) and (d). Peak profile analysis was performed for the $U_{\text {crystal }}^{4+}$ band near $4830 \mathrm{~cm}^{-1}$ and the $U_{\text {crystal }}^{4+}$ band near $6650 \mathrm{~cm}^{-1}$. The FWHM and peak position of the $\mathrm{U}_{\text {crystal }}^{4+}$ band are plotted as a function of temperature in figures 9(a) and (b). The data show that both spectral parameters begin to recover between 700 and $800 \mathrm{~K}$. We note that the frequency (figure 9(b)) exhibits a change like that observed in Raman spectra of the $\nu_{3}$ mode of $\mathrm{SiO}_{4}$ tetrahedra $\left(\mathrm{B}_{1 \mathrm{~g}}\right.$, antisymmetric stretching) (Zhang et al 2000c): a dramatic increase between 700 and $1100 \mathrm{~K}$ and temperature independence or weak dependence above $\sim 1100 \mathrm{~K}$.

The integral absorption coefficient (in units of $\mathrm{cm}^{-2}$ ) for the $\mathrm{U}_{\text {crystal }}^{5+}, \mathrm{U}_{\text {crystal }}^{4+}$ and $\mathrm{U}_{\text {amorphous }}$ signals was obtained (figures 10(a)-(c)). It is interesting that the $\mathrm{U}_{\text {crystal }}^{5+}$ signal near $6652 \mathrm{~cm}^{-1}$ shows an increase of $\sim 200 \%$ in intensity between 600 and $1200 \mathrm{~K}$, while the $\mathrm{U}_{\text {crystal }}^{4+}$ signal near $4830 \mathrm{~cm}^{-1}$ exhibits only $\sim 20 \%$ increase for the same temperature region, accompanied by an unexpected decrease in the intensity of signals from the amorphous domains beginning 


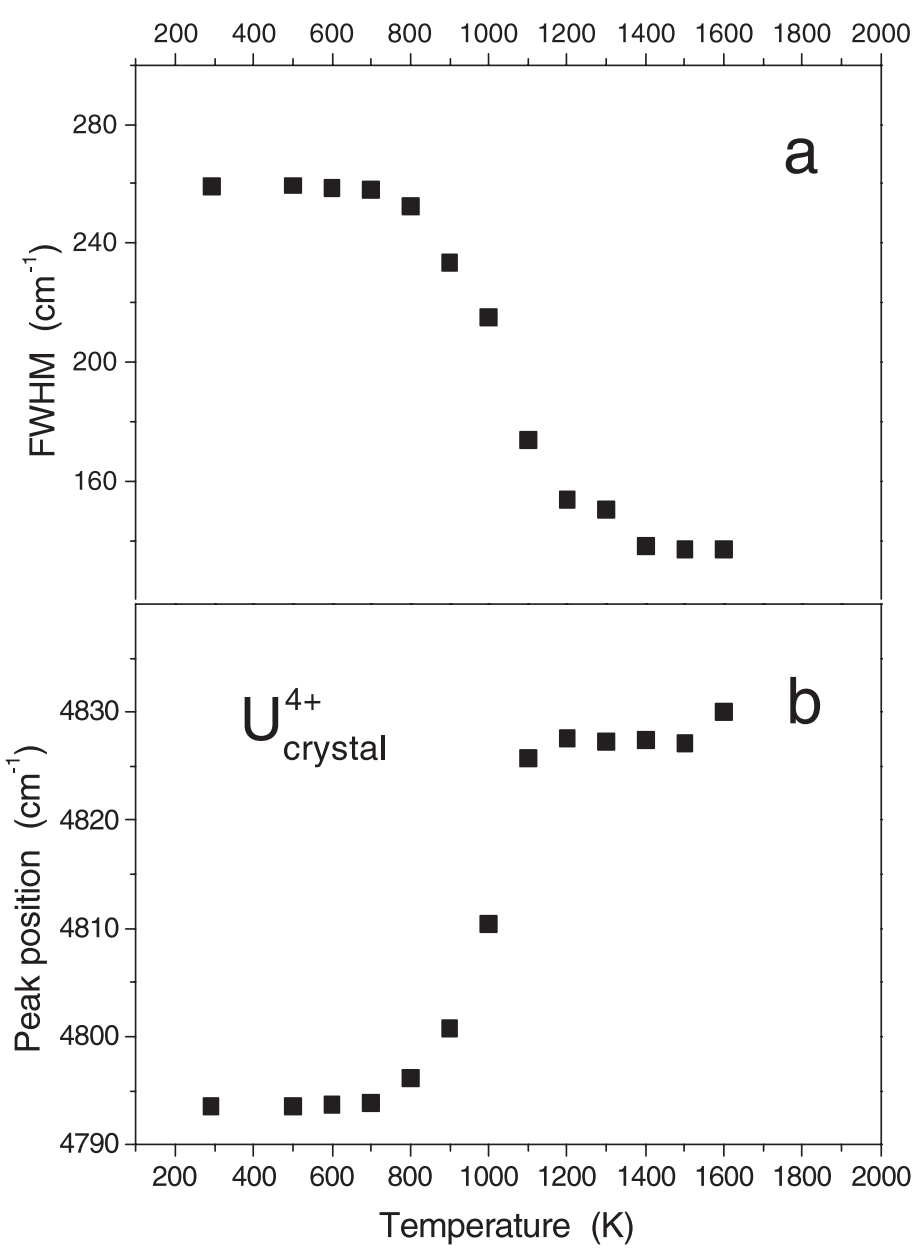

Figure 9. Temperature dependence of peak profiles of the $\mathrm{U}^{4+}$ band near $4832 \mathrm{~cm}^{-1}$ (sample Cam25). (a) FWHM and (b) peak position.

at $\sim 700 \mathrm{~K}$. The decrease is likely caused by epitaxial growth of the remaining crystalline domains in this moderately damaged sample. Epitaxial growth in radiation-damaged zircon has been previously reported in the polarized IR reflection study of Zhang et al (2000b), who observed the recovery of anisotropy along the original crystallographic orientations in damaged zircon on heating and a systematic increase in the reflectivity of zircon starting near $700 \mathrm{~K}$. Our results indicate a possible alteration of the charge state during thermal annealing. The ratios of band areas for $\mathrm{U}_{\text {crystal }}^{4+} / \mathrm{U}_{\text {crystal }}^{5+}$ and $\mathrm{U}_{\text {amorphous }} / \mathrm{U}_{\text {total }}$ were obtained and are shown as a function of annealing temperature in figures 11(a) and (b). The systematic changes in the intensity ratios on heating shown in figures 11(a) and (b) confirm that the changes shown in figures 4(a) and (b) are caused by radiation damage. The results show that the ratios of the different signals can be altered by thermal process.

The data of an annealed high-dose zircon crystal from Sri Lanka ( $\mathrm{Sd} 4$, with a dose of $15.9 \times 10^{18} \alpha$-events $\mathrm{g}^{-1}$ ) measured by Zhang et al (2002) was analysed in order to compare the thermal behaviours of $U$ ions in partially and highly metamict zircon. The crystal was annealed up to $1800 \mathrm{~K}$ in time steps of $1 \mathrm{~h}$ at different temperatures in a $\mathrm{N}_{2}$ atmosphere 


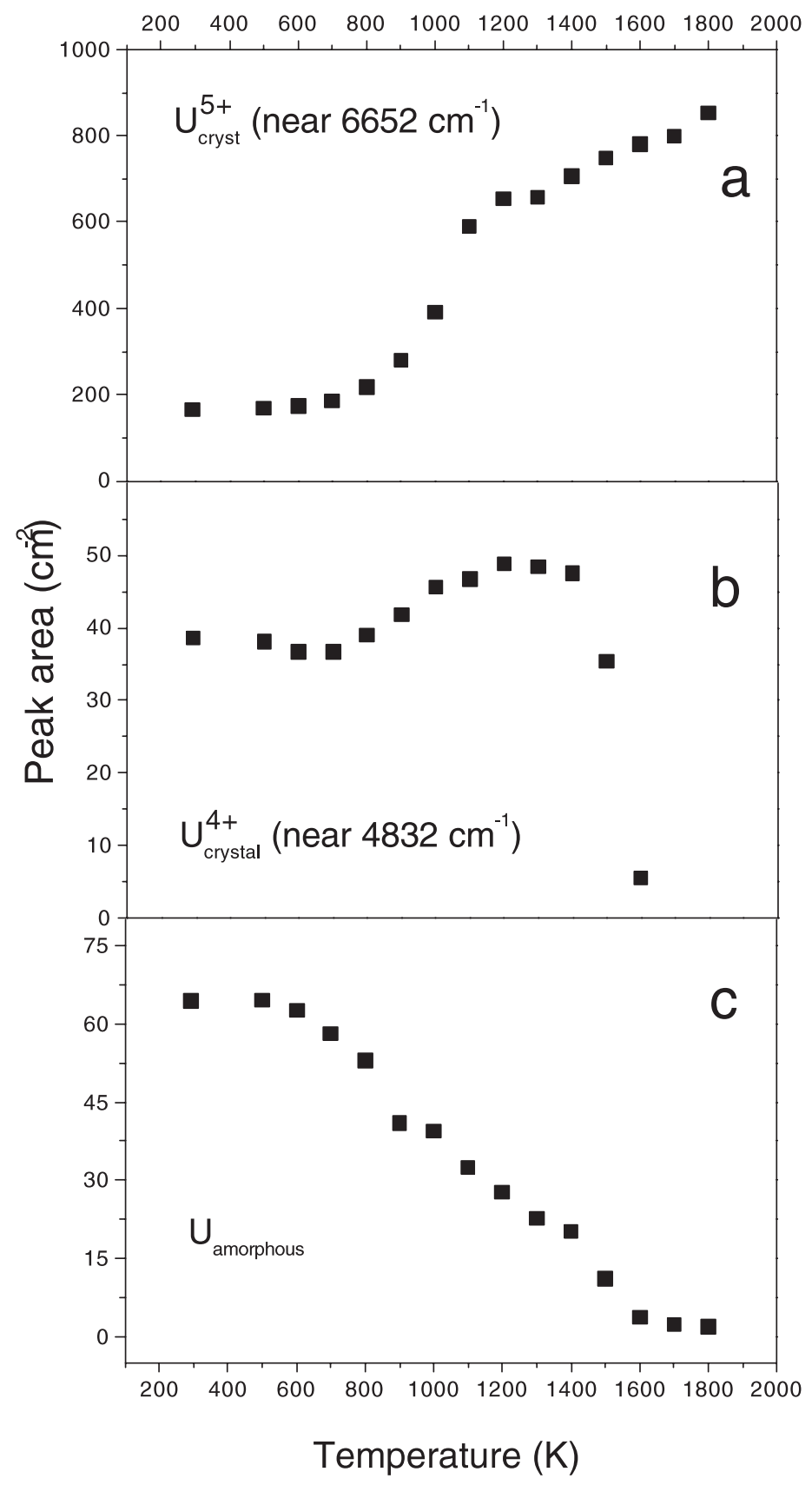

Figure 10. Temperature dependence of band areas (in units of $\mathrm{cm}^{-2}$ ) (sample Cam25): (a) $\mathrm{U}_{\text {crystal }}^{5+}$ near $6652 \mathrm{~cm}^{-1}(\boldsymbol{E} \perp c)$; (b) $\mathrm{U}_{\text {crystal }}^{4+}$ near $4832(\boldsymbol{E} \| c)$; and (c) signals due to $\mathrm{U}$ ions in the amorphous region. The data of $U_{\text {amorphous }}$ were obtained by integrating the absorption coefficient $(E \perp c)$ between 4000 and $5600 \mathrm{~cm}^{-1}$ in figure 8(c).

(figure 12). Due to the reasons explained in the experimental section, it was impossible to orient this high-dose sample crystallographically, and only unpolarized spectra were recorded. The 


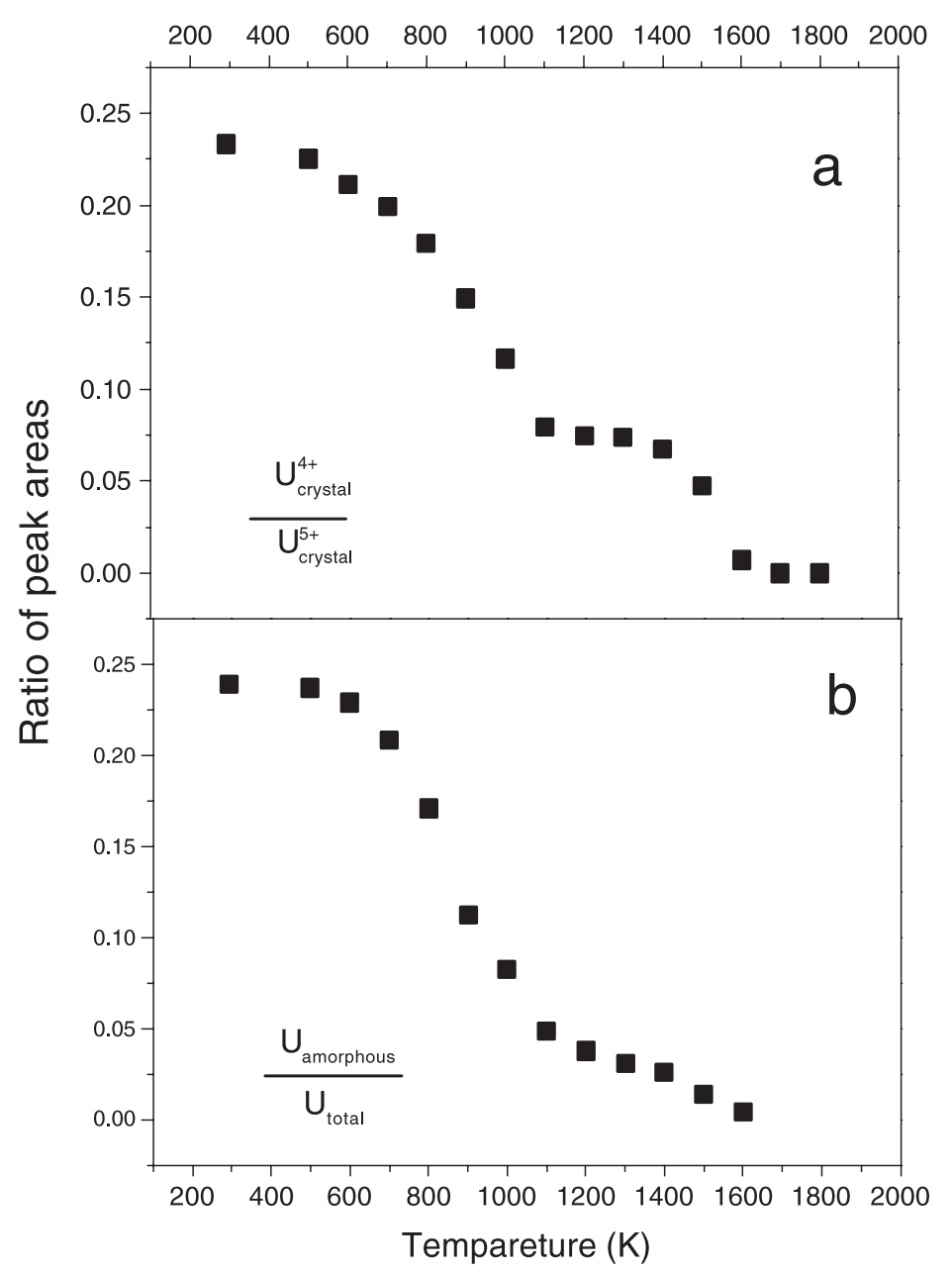

Figure 11. Ratio of band areas as a function of annealing temperature (sample Cam25): (a) $\mathrm{U}_{\text {crystal }}^{4+} / \mathrm{U}_{\text {crystal }}^{5+}$ and (b) $\mathrm{U}_{\text {amorphous }} / \mathrm{U}_{\text {total }}$.

structural recovery and recrystallization of the sample are characterized by infrared reflectance data on vibrations of $\mathrm{SiO}_{4}$ groups $\left(650-1400 \mathrm{~cm}^{-1}\right.$, room temperature-1800 K) and multiphonon spectra (1400-2500 $\mathrm{cm}^{-1}$ ) of the annealed sample (shown in the insets of figure 12). No significant spectral variations are detected at temperatures below $1000 \mathrm{~K}$. As shown in the inset of figure 12, a broad shoulder near $1948 \mathrm{~cm}^{-1}$ appears near $1100 \mathrm{~K}$. This feature becomes more visible in the $1200 \mathrm{~K}$ spectrum. This feature indicates the appearance of $\mathrm{SiO}_{2}$ glass resulting from the partial decomposition of this heated high-dose zircon (Zhang et al 2002). The thermal-induced decomposition was confirmed by Raman spectrum of this sample annealed at 1100 and $1200 \mathrm{~K}$, which shows the presence of tetragonal $\mathrm{ZrO}_{2}$. After annealing at 1400 and $1500 \mathrm{~K}$, the crystal shows the characteristic broad multi-phonon signals of crystalline $\mathrm{ZrSiO}_{4}$ near 1515, 1592, 1595, 1836, 1871, 1903, 1950 and $1992 \mathrm{~cm}^{-1}$ (obtained using the secondary-derivative method) (the right inset in figure 12), indicating the significant crystal growth of $\mathrm{ZrSiO}_{4}$. A sharpening of these curves and an increase in their intensity are observed with further increases in temperature. 


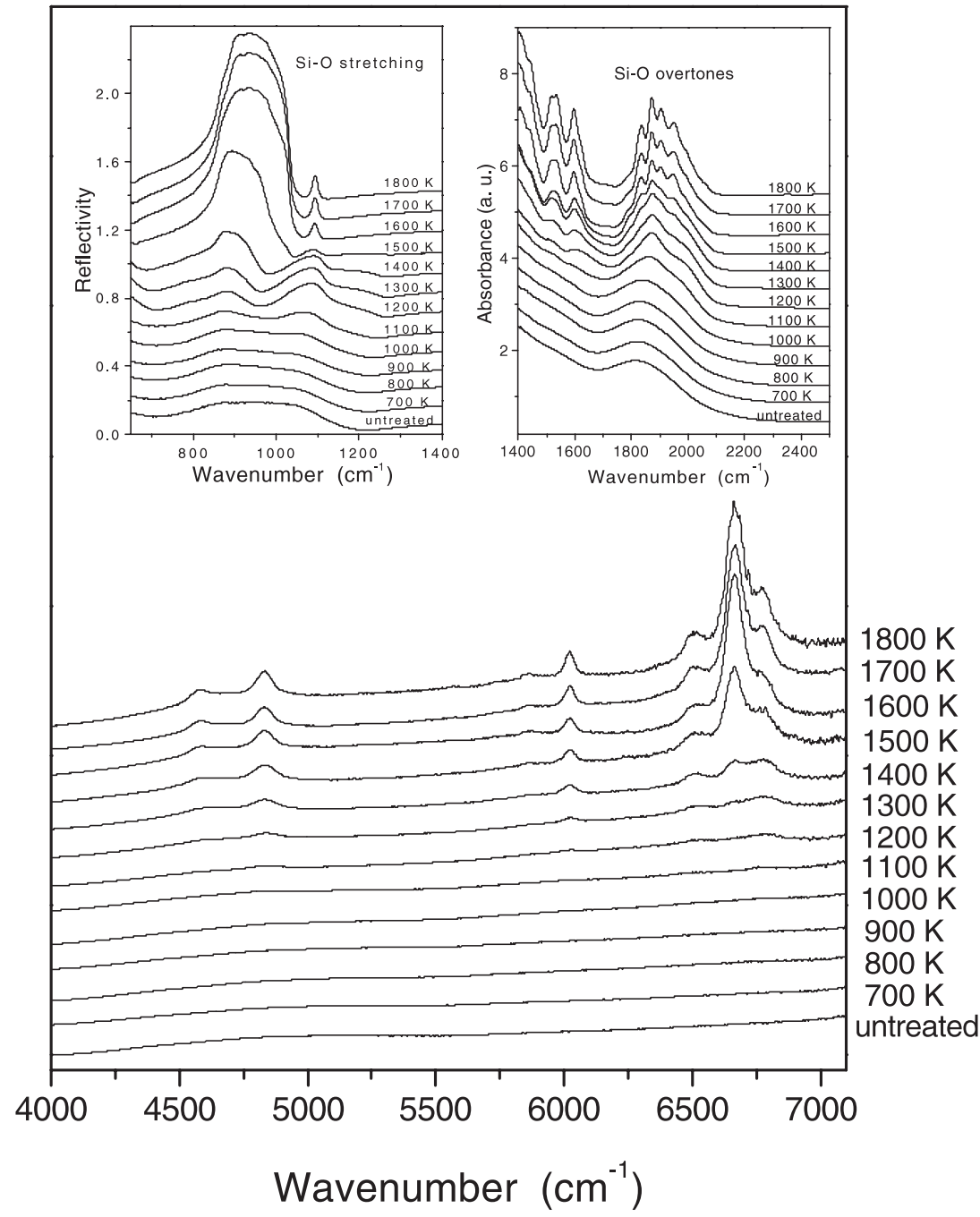

Figure 12. Unpolarized $U$ ion spectra of a highly metamict zircon (sample Sd4, dose $=\sim 15.9 \times 10^{18} \alpha$-events $\mathrm{g}^{-1}$ ) up to $1800 \mathrm{~K}$ (the data are from Zhang et al 2002). It was impossible to orient this high-dose sample crystallographically. The spectra were recorded using a Globar source, a KBr beamsplitter and a MCT detector.

Systematic changes in U spectra (figure 12) resulted from the recrystallization of this highly damaged zircon. In contrast to the thermal behaviour of the intermediately damaged zircon (Cam25), no significant spectral changes were recorded below $\sim 1000 \mathrm{~K}$, i.e. the spectra of this highly damaged zircon were still dominated by broad features related to those in the amorphous domains at these temperatures. This implies that the thermal behaviour depends on the degree of initial damage in the sample. Weak and relatively sharp $U$ ion signals became detectable between 1100 and $1300 \mathrm{~K}$. Further heating resulted in a dramatic increase in the intensity of the signals, especially for $U_{\text {crystal }}^{5+}$ bands. The integrated absorbance of the $4830 \mathrm{~cm}^{-1}\left(\mathrm{U}_{\text {crystal }}^{4+}\right)$ and the $6652 \mathrm{~cm}^{-1}\left(\mathrm{U}_{\text {crystal }}^{5+}\right)$ signals was extracted through curve fitting to show the effect of annealing temperature (figure 13(a)). The dramatic increase of $U$ ion signals that occurred near $1400 \mathrm{~K}$ (figure 12) is explained as an indication of the growth of $\mathrm{ZrSiO}_{4}$ resulting from 


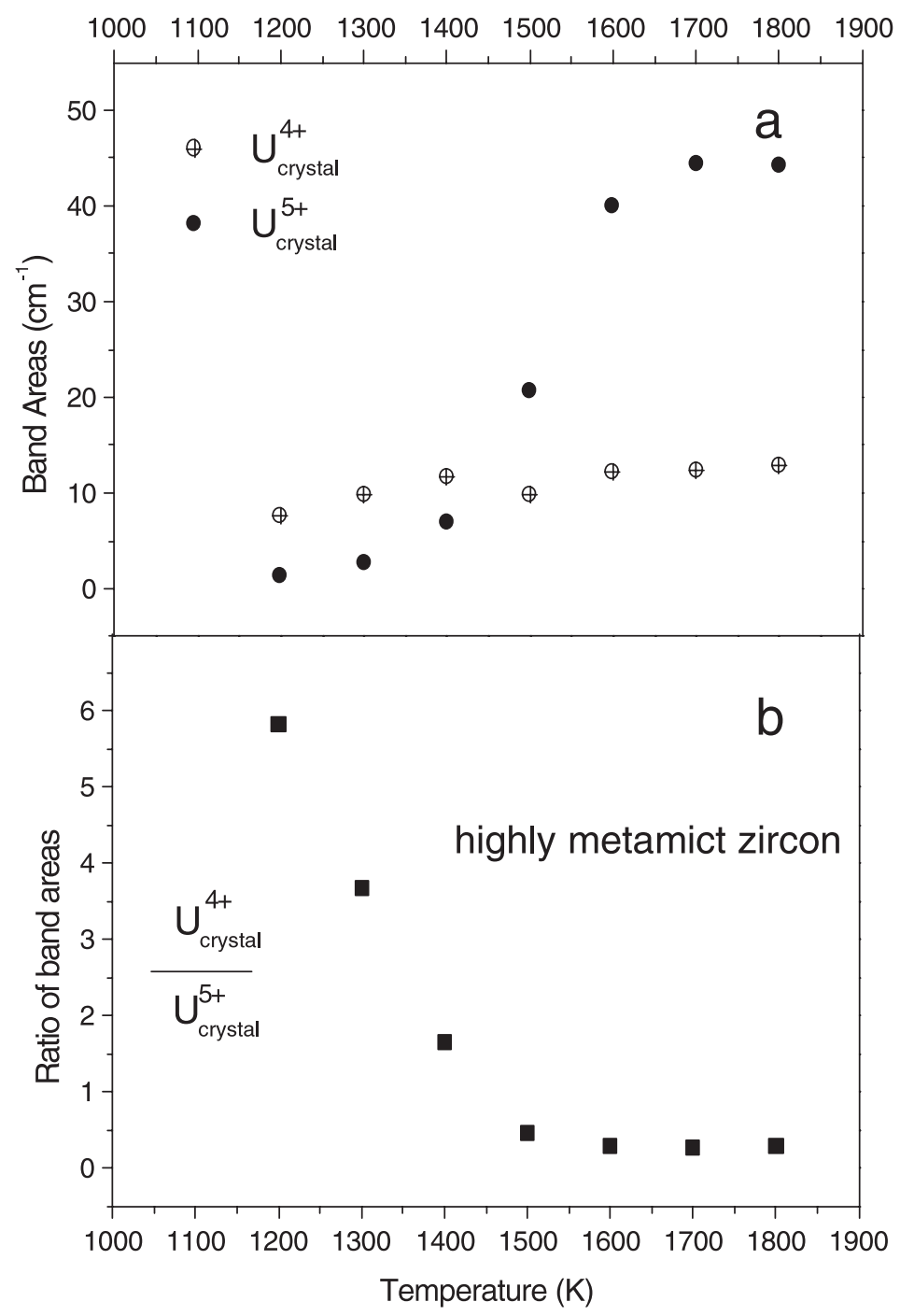

Figure 13. Temperature dependence of band areas and ratio of band areas of the highly damaged zircon Sd4. (a) Band areas of the $\mathrm{U}_{\text {crystal }}^{5+}$ signal near $6652 \mathrm{~cm}^{-1}$ and the $\mathrm{U}_{\text {crystal }}^{4+}$ signal near $4830 \mathrm{~cm}^{-1}$; and (b) $\mathrm{U}_{\text {crystal }}^{4+} / \mathrm{U}_{\text {crystal }}^{5+}$.

the reaction of $\mathrm{ZrO}_{2}$ and $\mathrm{SiO}_{2}$ (Zhang et al 2002). Our data show that the oxidation state of uranium in metamict zircon can be dramatically altered in metamictization and thermal annealing.

\section{Discussion}

Our analysis demonstrates that the $\mathrm{U}$ ion signals of metamict zircon can be simplified into two types with different structural origins:

(1) lines from $\mathrm{U}$ ions $\left(\mathrm{U}_{\text {crystal }}^{4+}\right.$ and $\mathrm{U}_{\text {crystal }}^{5+}$ ) in the remaining crystalline regions showing anisotropic and relative sharp bands, and 
(2) absorption of $U$ ions ( $U_{\text {amorphous }}$, mainly in tetravalent state) from amorphous materials exhibiting broad and isotropic spectral features.

With changing radiation dose, the systematic change in intensity ratio between these two types of signals (figure 4(b)) is essentially associated with the change of the volumes of the two types of material (although, strictly, it does not represent the fraction of the amorphous materials), in contrast to the change between $\mathrm{U}_{\text {crystal }}^{4+}$ and $\mathrm{U}_{\text {crystal }}^{5+}$ caused by radiation-induced ionization. This result is supported by the opposite changes in the two types of signal during radiation damage and thermal annealing. We believe that in damaged zircon the $U$ ions associated with the $\mathrm{U}_{\text {crystal }}^{4+}$ and $\mathrm{U}_{\text {crystal }}^{5+}$ signals occupy structural sites ( $\mathrm{U}$ for $\mathrm{Zr}$ ) in $\mathrm{ZrSiO}_{4}$ and the local structure is defective and distorted by radiation. In unannealed zircons, a majority portion of these $\mathrm{U}_{\text {crystal }}^{4+}$ and $\mathrm{U}_{\text {crystal }}^{5+}$ ions could enter the $\mathrm{Zr}^{4+}$ sites when the crystal first forms (of course, $\mathrm{U}_{\text {crystal }}^{5+}$ is charge compensated). The original ratio of $\mathrm{U}_{\text {crystal }}^{4+}$ and $\mathrm{U}_{\text {crystal }}^{5+}$ might depend on the growth conditions (e.g. temperature and pressure). This means that $\mathrm{U}_{\text {crystal }}^{4+}$ and $\mathrm{U}_{\text {crystal }}^{5+}$ are more likely associated with ${ }^{238} \mathrm{U}$ and ${ }^{235} \mathrm{U}$ ions in crystalline regions (if neglecting radiogenic $\mathrm{U}$ ions). Please note that our data shown in figure 4(b) suggest radiogenic U ions might also be present in crystalline regions (see later discussions).

The $\mathrm{U}_{\text {amorphous }}$ ions in the glassy/amorphous materials, however, are formed through a different process. It is generally accepted that the recoils $(\sim 0.7 \mathrm{MeV})$ produced during $\alpha$ decay events are mainly responsible for the formation of the amorphous domains in metamict zircon (Weber et al 1988). As the crystalline and amorphous states in zircon are very different structurally, these U ions in amorphous regions must have undergone structural rearrangements, and they are no longer associated with their original local configurations formed at the time of crystallization. Although there is a lack of knowledge of the local structure of the amorphous domains, it is clear that long and medium order of the crystal structure of zircon is destroyed or lost (Murakami et al 1991, Weber et al 1988, Salje et al 1999, Zhang and Salje 2001). At this stage, we can attribute the $U_{\text {amorphous }}$ to different types of $U$ ions with different types of sources: radiogenic $U$ ions through alpha decays (e.g. ${ }^{234} \mathrm{U}$ ions) and undecayed $\mathrm{U}$ ions $\left({ }^{238} \mathrm{U}\right.$ and ${ }^{235} \mathrm{U}$ ) that are in the way of the high-energy recoils or located within the recoil-impact areas. They are more likely to be affected by different processes (e.g. hydrothermal alteration, dissolution, and weathering) because of the amorphous structure. Recent experimental results (Davis and Krogh 2000) reported preferential dissolution of ${ }^{234} \mathrm{U}$ from radiation-damaged zircon. Leaching of $\mathrm{U}$, Th and radiogenic daughters from monazite was documented by Eyal and Olander (1990) and Olander and Eyal (1990a, 1990b).

The results in figure 4(b) show that the dose dependence of the ratio of $U_{\text {amorphous }} / U_{\text {total }}$ does not follow that of the fraction of the amorphous domain, but gave clearly lower values. The apparent suggestion of the data is that a lower portion of $U$ ions is found in the amorphous domains as compared to the fraction of amorphous material. If this is true, the direct implication from the results is the preferential occurrence of $U$ ions or possible $U$ enrichment in the crystalline regions. The physics behind the difference between the data of the fraction and the $\mathrm{U}_{\text {amorphous }} / \mathrm{U}_{\text {total }}$ appears complex. Based on the data, one may speculate whether some ${ }^{234} \mathrm{U}$ ions (e.g. produced in the decay of Th) appear in the crystalline region of the damaged zircon (or possibly end up in the $\mathrm{Zr}^{4+}$ sites) or some of the $\mathrm{U}$ ions in amorphous materials were somehow leached out during geological periods. The latter does not seem the case for the Sri Lanka zircon gem crystals used in this study because they showed very low $\mathrm{OH}$ or $\mathrm{H}_{2} \mathrm{O}$ contents (Woodhead et al 1991a, 1991b, Zhang et al 2002) and the data from the mid-IR region (Zhang and Salje 2001) do not show characteristic spectral features seen recently in fluid-altered zircons produced through hydrothermal leach experiments (Geisler et al 2003). The understanding of the data in figure 4(b) is further complicated by other factors related to 
the radiation damage in metamict zircon. For instance, the amorphous materials in metamict zircon are produced by the $\alpha$-decay radiation of $\mathrm{U}$, Th and their daughter products, but the data shown in figure 4(b) are mainly associated with $U$ ions. The other issue one might need to take into account is whether the molar absorption coefficients of the different $U$ ions remain constant even in the whole dose region (or whether radiation damage leads to changes of the molar absorption coefficients). These complex issues are beyond the scope of this study and more work is desirable.

We shall focus on the radiation-induced changes associated with the $U$ ions in the crystalline materials (i.e. $\mathrm{U}_{\text {crystal }}^{4+}$ and $\mathrm{U}_{\text {crystal }}^{5+}$ ). One important issue related to the metamictization process in zircon is the nature behind some similarities between the results of $U$ ion spectra and phonon spectra (e.g. Raman spectra) of zircon. As shown in figures 3(b) and (c), the frequencies of the $U$ ion bands exhibited a systematic decrease in the dose region of $\sim 0$ and $\sim 3.5\left(10^{18} \alpha\right.$-events $\left.\mathrm{g}^{-1}\right)$. A similar change was reported in a Raman study on phonon modes of damaged zircons (Zhang et al 2000c). These authors showed that crystalline zircon exhibited a Raman band near $1007 \mathrm{~cm}^{-1}$ (internal $\nu_{3}$ band of $\mathrm{SiO}_{4}$ ) and its frequency lowered to $\sim 995 \mathrm{~cm}^{-1}$ with increasing dose up to $\sim 3.5\left(10^{18} \alpha\right.$-events $\left.\mathrm{g}^{-1}\right)$ as a result of percolation of the amorphous phases (Salje et al 1999). On annealing, the frequency of the Raman band recovered (Zhang et al 2000a). As these two types of spectroscopic methods reveal information from different length scales (phonon spectra are associated with molecular/atomic vibrations, whereas $U$ ion spectra are related to electronic transitions), the similar changes in both types of spectra probably reflect the same physical origin from different aspects, and it is impossible that these anomalies, detected by different analytic methods, could appear accidentally in the same dose region. The change in $U$ ion spectra likely results from the radiation-induced defective structure of zircon revealed by x-ray diffraction and vibrational spectroscopy (Murakami et al 1991, Zhang et al 2000a, 2000c). The radiation-induced changes in the defective zircon lattice are shown in U spectra through the strong coupling between the electronic transitions within the $\mathrm{f}$ band and the vibrations of the host lattice in materials with zircon structure (Lahalle et al 1986). Another possible cause is the potential alteration of the averaged symmetry $\left(D_{2 d}\right)$ of a $\mathrm{Zr}^{4+}$ site in damaged zircon, as high concentrations of impurities can result in the breaking of the site symmetry. Unfortunately, there is a lack of experimental investigations into this issue because of its complexity.

With increasing metamictization, the increase in the signal ratio between tetravalent and pentavalent $\mathrm{U}$ ions in crystalline domains (figure 4(a)) and the observation of dominated $\mathrm{U}^{4+}$ signals in amorphous domains (figure 1(a)) indicate that the tetravalent state (i.e. with electronic charge of $4+$ ) is the preferable oxidation state of $U$ ions in metamict zircon. The increase in the ratio of $\mathrm{U}_{\text {crystal }}^{4+} / \mathrm{U}_{\text {crystal }}^{5+}$ can be explained as trapping electrons by the pentavalent $U$ ions and changing to the tetravalent state. On heating the trapped electron could be released and leads to the decrease in the ratio of $U_{\text {crystal }}^{4+} / U_{\text {crystal }}^{5+}$ as shown in figures 11(a) and 13(b). In this case the electrons are expected to be deeply trapped, in contrast to those trapped by other defects (e.g. see below), as on heating the change in $\mathrm{U}_{\text {crystal }}^{4+} / \mathrm{U}_{\text {crystal }}^{5+}$ appeared above $700 \mathrm{~K}$. The change could also be the result of a radiation-induced change of local structures, which could lead to modifications of the local configurations associated with $\mathrm{Zr}^{4+}$ and $\mathrm{Si}^{4+}$ sites.

The results of this study shed light on several aspects of the crystal chemistry of zircon and the issues could have significant implications in geology and mineralogy.

(1) As pointed out by Zhang et al (2002), ionization may occur during radioactive decay (i.e. $\alpha$-, $\beta$ - and $\gamma$-decays), causing variations of the charge state of lattice defects. To gain further understanding of radiation-induced changes in valence states of metamict materials is of importance as these changes may play a significant role in the microstructural 
evolution of irradiated materials and result in changes in other physical properties (Ewing 2001). As a result, the mobility of the defects may be affected (Bourgoin and Corbett 1978) and eventually the chemical durability and dissolution rate may be altered. This may affect the leaching behaviour of natural zircon and the related diffusion processes. In addition, the modification of charge states can change the local configurations associated with hydrous components and give rise to new sites for $\mathrm{OH}$ species in zircon. Thus, element migration in metamict materials is a critical issue for candidate materials proposed for the immobilization and stabilization of nuclear waste forms. Our observations of radiationinduced ionization in metamict zircon draw our attention to several important questions, such as whether the ionization may possibly influence the diffusion and leach behaviour of trace elements, especially on $\mathrm{U}$ and $\mathrm{Pb}$ ions, in natural zircon, or whether the different types of $\mathrm{U}$ ion components (e.g. $\mathrm{U}_{\text {amorphous }}, \mathrm{U}_{\text {crystal }}^{4+}, \mathrm{U}_{\text {crystal }}^{5+}$ ) exhibit different diffusion behaviour. It appears reasonable to think that $U_{\text {amorphous }}$ can be more easily leached out from metamict zircon, compared with $\mathrm{U}_{\text {crystal }}^{4+}$ and $\mathrm{U}_{\text {crystal }}^{5+}$, as damaged zircons generally show much high leach rates (Ewing et al 1982) and the $U$ ions in amorphous materials should have weaker interactions with other atoms and poorly defined crystal fields. Based on the general concept of ions, we can predict that $U_{\text {crystal }}^{4+}$ and $U_{\text {crystal }}^{5+}$ should have different diffusion rates because of their different ionic radii. Ions with smaller ionic radius may show higher diffusion coefficients and better mobility, although we have no knowledge on whether there is a preferential loss between $\mathrm{U}_{\text {crystal }}^{4+}$ and $\mathrm{U}_{\text {crystal }}^{5+}$.

(2) Investigations into defects or impurities-related charge states may shed light on the nature of site occupancies and the forms of the relevant charge compensation occurring as a result of radiation damage. In general, when cations with different valence states appear in the zircon structure, oxygen vacancies or hole formations are required for charge compensation to neutralize the system. Radiation damage may lead to changes of crystal fields near the cation sites, migrations of different vacancies/holes and electron trapping with defects. Similar to the change of $U$ ions in zircon, the alteration of the charge states for Dy and $\mathrm{Tb}$ ions $\left(\mathrm{Dy}^{3+} \leftrightarrow \mathrm{Dy}^{4+}\right.$ and $\mathrm{Tb}^{3+} \leftrightarrow \mathrm{Tb}^{4+}$ ) was documented in irradiated and annealed zircon (Laruhin et al 2002). To gain a better understanding of the oxidation state of $\mathrm{Pu}$ in $\mathrm{Pu}$-doped zircon and the potential alteration of the valence state is of considerable importance as zircon has been proposed as a waste form for the disposal of plutonium from dismantled nuclear weapons (Burakov 1993, Anderson et al 1993, Ewing et al 1995, Weber et al 1996, Ewing 1999). Plutonium may exist in different valence states (e.g. 3+, 4+, 5+ and 6+) (see, e.g., Conradson et al 1998). In Pu-doped zircon $\mathrm{Pu}$ sits in the $\mathrm{Zr}^{4+}$ site (with a symmetry of $\mathrm{D}_{2 \mathrm{~d}}$ ) through chemical substitutions. As oxidation or reduction can result in a significant variation in structural distortion due to the change in ionic size mismatch between cations with different charges on the $\mathrm{Zr}^{4+}$ sites, the structural parameters can be altered remarkably. For instance, data from crystalline ${ }^{239} \mathrm{Pu}$-substituted zircon (Begg et al 2000) showed that annealing the crystalline sample at $1200^{\circ} \mathrm{C}$ for $12 \mathrm{~h}$ in air led to the oxidation of $\mathrm{Pu}^{3+}$ (the trivalent state of $\mathrm{Pu}$ in the zircon was an unexpected result of originally preparing the $\mathrm{Pu}$-substituted zircon under a reducing atmosphere) to $\mathrm{Pu}^{4+}$ and this resulted in the decrease of the cell volume from 267.8 to $262.3 \AA^{3}$. The relative large ionic radius of $\mathrm{Pu}^{3+}$ (the ionic radius of plutonium ions can be $\sim 0.100$ and $\sim 0.086 \AA$ for $\mathrm{Pu}^{3+}$ and $\mathrm{Pu}^{4+}$, respectively (Shannon 1976, Williford et al 2000), in comparison to $0.79 \AA$ for $\mathrm{Zr}^{4+}$ (Akhtar and Waseem 2001)) might also alter the preferred mechanism for incorporation of these ions into the zircon lattice. Computer simulation (Williford et al 2000) has shown that two $\mathrm{Pu}^{3+}$ ions can be charge compensated by an oxygen vacancy, although $\mathrm{Pu}^{4+}$ substitution of $\mathrm{Zr}^{4+}$ has the lowest energy. Investigations have shown that relatively low energy irradiation (e.g. $\gamma$-ray irradiation) can cause other defect centres in 
zircon. The formation of $\mathrm{SiO}_{m}^{n-}$ defects in zircon were reported in different studies (Barker and Hutton 1973, Solntsev et al 1974, Laruhin et al 2002). During irradiation, some of the oxide ions in the zircon crystal structure lose an electron, which can be trapped by silicon oxide groups forming $\mathrm{SiO}_{4}^{5-}, \mathrm{SiO}_{2}^{3-}$ and $\mathrm{SiO}_{2}^{-}$. Some of the radicals were stabilized by a $\mathrm{Zr}$ vacancy or by some atom incorporated substitutionally for $\mathrm{Zr}$ in the lattice of $\mathrm{ZrSiO}_{4}$. However, these defects are less stable upon heating compared to our case because these defects act as shallow electron/hole traps. EPR (electron paramagnetic resonance) data of irradiated zircons showed that these $\mathrm{SiO}_{m}^{n-}$ defect centres can be annealed at temperatures between 373 and $423 \mathrm{~K}$ (Laruhin et al 2002). The presence of these different defects in natural zircons and their disappearance at different temperatures on heating may provide a potential means to examine the thermal history of the host rocks.

(3) To gain better understanding of radiation-induced ionization is important for theoretical simulations in studies in petrology and mineralogy, as different trace REEs (rare-earth element) in natural zircon have been commonly used for modelling of petrogenetic process and metamorphism. One of the examples is the use of REEs to determine partition coefficients of zircon/melt and to study the composition of the melt from which the zircon host crystallized. Previous studies showed that zircon/melt partition coefficients strongly depend on cation radius and their values can vary over several orders when the cation radius changes from 0.97 to $1.15 \AA$ (Watson 1980, Murali et al 1983, Fujimaki 1986, Thomas et al 2002). However, the different valence states of REEs in zircon were reported (e.g. Gaft et al 2000, Akhtar and Waseem 2001, Laruhin et al 2002) and they can potentially result in problems. For instance, in zircon, Ce ions are in the form of $\mathrm{Ce}^{4+}$ and $\mathrm{Ce}^{3+}$. The commonly obtained partition coefficient for Ce represents an apparent coefficient that includes both $\mathrm{Ce}^{4+}$ and $\mathrm{Ce}^{3+}$. However, the different ionic radii between $\mathrm{Ce}^{4+}$ and $\mathrm{Ce}^{3+}\left(\mathrm{Ce}^{4+}=0.97 \AA\right.$ and $\left.\mathrm{Ce}^{3+}=1.143 \AA\right)$ result in a considerable difference between the partition coefficients of $\mathrm{Ce}^{3+}$ and $\mathrm{Ce}^{4+}\left(D_{\mathrm{Ce}^{3+}}=0.14\right.$ and $\left.D_{\mathrm{Ce}^{4+}}=102.6\right)$ (Thomas et al 2002). Any potential change of the charge state between two types of ions caused by radiation over geological periods could alter the results of natural systems and consequently complicate data interpretation and theoretical modelling.

\section{Acknowledgments}

The authors would like to thank Steve Laurie at the Sedgwick Museum (University of Cambridge, UK), Andrew Clark and Mark Welch at the Natural History Museum (London, UK) and Jochen Schlüter at the Mineralogisches Museum (Universität Hamburg, Germany) for providing some of the samples used in this study. Thanks are due to William Lee for reading the original manuscript. Financial funding from British Nuclear Fuels (BNFL) and the Cambridge-MIT Institute (CMI) is gratefully acknowledged. RCE gratefully acknowledges financial support from the US Department of Energy, Office of Basic Energy Sciences (DEFG02-97ER45656).

\section{References}

Akhtar M J and Waseem S 2001 Chem. Phys. 274109

Anderson B W 1962 Gemmologist 3119

Anderson B W 1963 J. Gemmol. 91

Anderson B W and Payne C J 1939 Gemmologist 9

Anderson E B, Burakov B E and Vasiliev V G 1993 Proc. Safe Waste' 9322

Barker V P and Hutton D R 1973 Phys. Status Solidi b 60 K109

Begg B D, Hess N J, Weber W J, Conradson S D, Scheiger M J and Ewing R C 2000 J. Nucl. Mater. 278212 
Bourgoin J C and Corbett J W 1978 Radiation Effects 36157

Burakov B E 1993 Proc. Safe Waste '93 219

Carrigan C W, Miller C F, Fullagar P D, Bream B R, Hatcher R D Jr and Coath C D 2003 Precambrian Res. 1201

Chapman H J and Roddick J C 1994 Earth Planet. Sci. Lett. 121601

Conradson S D, Al Mahamid I, Clark D L, Hess N J, Hudson E A, Neu M P, Palmer P D, Runde W H and Tait C D 1998 Polyhedron 17599

Davis D W and Krogh T E 2000 Chem. Geol. 17241

Ellsworth H V 1925 Am. J. Sci. 209127

Ellsworth S, Navrotsky A and Ewing R C 1994 Phys. Chem. Minerals 21140

Ewing R C 1994 Nucl. Instrum. Methods Phys. Res. B 9122

Ewing R C 1999 Proc. Natl Acad. Sci., USA 963432

Ewing R C 2001 Can. Mineral. 39697

Ewing R C, Haaker R F and Lutze W 1982 Mater. Res. Soc. Symp. Proc. 11389

Ewing R C, Lutze W and Weber W J 1995 J. Mater. Res. 10243

Eyal Y and Olander D R 1990 Geochim. Cosmochim. Acta 541867

Farnan I and Salje E K H 2001 J. Appl. Phys. 892084

Frondel C 1958 US Geol. Surv. Bull. 1064400

Fujimaki H 1986 Contrib. Mineral. Petrol. 9442

Gaft M, Panczer G, Reisfeld R and Shinno I 2000 J. Alloys Compounds 330/301 267

Geisler T, Pidgeon R T, van Bronswijk W and Kurtz R 2002 Chem. Geol. 191141

Geisler T, Zhang M and Salje E K H 2003 J. Nucl. Mater. at press

Holland H D and Gottfried D 1955 Acta Crystallogr. 8291

Hutton C O 1950 Bull. Geol. Soc. Am. 61635

Judd B R and Runciman W A 1976 Proc. R. Soc. A 35291

Kisliuk P, Richman I and Wong E Y 1967 Absorption spectrum of $\mathrm{U}^{4+}$ in zircon $\left(\mathrm{ZrSiO}_{4}\right)$ Optical Properties of Ions in Crystals ed H M Crosswhite and H W Moos (New York: Wiley-Interscience) p 537

Lahalle M P, Krupa J C, Lepostollec M and Forgerit J P 1986 J. Solid State Chem. 64181

Laruhin M A, van Es H J, Bulka G R, Turkin A A, Vainshtein D I and den Hartog H W 2002 J. Phys.: Condens. Matter 143813

Mackey D J, Runciman W A and Vance E R 1975 Phys. Rev. 155262

Meldrum A, Zinkle S J, Boatner L A and Ewing R C 1998 Nature 39556

Murali AV, Parthasarathy R, Mahadevan TM and Sankar D 1983 Geochim. Cosmochim. Acta 472047

Murakami T, Chakoumakos B C, Ewing R C, Lumpkin G R and Weber W J 1991 Am. Mineral. 761510

Olander D R and Eyal Y 1990a Geochim. Cosmochim. Acta 541879

Olander D R and Eyal Y 1990b Geochim. Cosmochim. Acta $\mathbf{5 4} 1889$

Richman I, Kisliuk P and Wong E Y 1967 Phys. Rev. 155262

Ríos S and Salje E K H 1999 J. Phys.: Condens. Matter 118947

Ríos S, Salje E K H, Zhang M and Ewing R C 2000 J. Phys.: Condens. Matter 122401

Salje E K H, Chrosch J and Ewing R C 1999 Am. Mineral. 841107

Salje E K H, Zhang M and Groat L A 2000 Phase Transit. 71173

Shannon R D 1976 Acta Crystallogr. A 32751

Solntsev V P, Shcherbakova M Y and Dvornikov E V 1974 J. Struct. Chem. 15217

Speer J A 1980 Zircon Orthosilicates (Rev. Mineral) vol 5, ed P H Ribbe p 67

Thomas J B, Bodnar R J, Shimizu N and Sinha A K 2002 Geochim. Cosmochim. Acta 662887

Tomkeleff S I 1946 Sci. Prog. 36696

Vance E R and Mackey D J 1974 J. Phys. C: Solid State Phys. 71898

Vance E R and Mackey D J 1975 J. Phys. C: Solid State Phys. 83439

Vance E R and Mackey D J 1978 Phys. Rev. B 18185

Watson E B 1980 Geochim. Cosmochim. Acta 44895

Weber W J, Ewing R C, Catlow C R A, de la Rubia T D, Hobbs L W, Kinoshita C, Matzke H, Motta A T, Nastasi M, Salje E H K, Vance E R and Zinkle S J 1998 J. Mater. Res. 131434

Weber W J, Ewing R C and Lutze W 1996 Mater. Res. Soc. Symp. Proc. 41225

Williford R E, Begg B D, Weber W J and Hess N J 2000 J. Nucl. Mater. 278207

Woodhead J A, Rossman G R and Silver L T 1991a Am. Mineral. 7674

Woodhead J A, Rossman G R and Thomas A P 1991b Am. Mineral. 761533

Zhang M, Lee G A, Salje E K H and Beran A 2001 Am. Mineral. 86904

Zhang M and Salje E K H 2001 J. Phys.: Condens. Matter 133057

Zhang M and Salje E K H 2003 Phase Transit. 76117 
Zhang M, Salje E K H, Capitani G C, Leroux H, Clark A M and Schlüter J 2000a J. Phys.: Condens. Matter 123131 Zhang M, Salje E K H and Ewing R C 2002 J. Phys.: Condens. Matter 143333

Zhang M, Salje E K H, Ewing R C, Farnan I, Ríos S, Schlüter J and Leggo P 2000b J. Phys.: Condens. Matter 12 5189

Zhang M, Salje E K H, Farnan I, Graeme-Barber A, Daniel P, Ewing R C, Clark A M and Leroux H 2000c J. Phys.: Condens. Matter 121915

Zhang M, Salje E K H, Malcherek T, Bismayer U and Groat L A 2000d Can. Mineral. 38119

Zhang M, Wruck B, Graeme-Barber A, Salje E K H and Carpenter M A 1996 Am. Mineral. 8192 